ESTUDIOS 

REVISTA DE DERECHO UNED, NÚM. 13, 2013

\title{
DEMOCRACIA VERSUS TUTELA JUDICIAL, DERECHO A LA DEFENSA Y TIEMPO PROCESAL
}

\author{
DEMOCRACY VERSUS EFFECTIVE PROTECTION OF THE \\ COURT, RIGHT DEFENSE AND PROCEDURAL TIME
}

\author{
María de los Reyes Albert Silvestre \\ (Doctoranda U.E. Fac. UNED) \\ ralbert@telefonica.net \\ Valencia, 8 de noviembre de 2013
}

\begin{abstract}
Resumen: Frente al problema del desprestigio del orden judicial actual nos planteamos la conveniencia de conocer cuáles son los rasgos comunes, los tres pilares que deben orientar cualquier sistema jurisdiccional justo, como son el Derecho de Defensa, la Tutela Judicial Efectiva y el Tiempo Judicial. Después nos detenemos en las consecuencias de ese problema y como puede corregirse a nivel de la Unión Europea de acuerdo con el objetivo de alcanzar «Una Europa de la Ley y de la Justicia», tal como lo establece el PROGRAMA DE ESTOCOLMO.
\end{abstract}

En consecuencia, el Derecho a la Tutela Judicial constituye la base fundamental del Estado de Derecho, soportado constitucionalmente (justicia, seguridad jurídica, legalidad, etc.) y articula las garantías individuales subyacentes en los procesos jurisdiccionales.

Así, pues, el acceso a la Justicia, avalado por la existencia de una Tutela Judicial Efectiva a título personal y de un Control Jurisdiccional sobre las Administraciones Públicas son manifestaciones de la escala de valores que sustenta al moderno Estado Social y Democrático de Derecho y son percibidas por la Sociedad Civil como factores constitutivos de su legitimación política, de tal forma que cuando dichas manifestaciones se deprecian socialmente, se produce un distanciamiento entre las Instituciones y las personas físicas, que nada bueno presagian, según la histórica experiencia europea. 
Abstract: Meet the discredit of the judicial current order problem we think about the convenience of knowing which the common features are, it means, the three pillars that should guide any jurisdictional fair system, like the defense right, effective protection of the court and the procedural time. Then we stop in the consequences of that problem and like it can be corrected inside the European Union with the objective of reaching «An Europe of the Law and the Justice», just as it the PROGRAM DE STOCKHOLM establishes.

By that, the effective protection of the court constitutes the fundamental base of the State of Right, supported constitutionally (justice, artificial security, legality, etc.) and it articulates the individual underlying guarantees in the jurisdictional processes.

This way, because the access to the Justice, endorsed by the effective protection of the court to personal title and a Jurisdictional Control on the Public Administrations are manifestations of the scale of values that sustains the modern social and democratic state of right and they are perceived by the civil society as constituent factors of the political legitimation; when this manifestations are depreciated socially, a distancing takes place between the Institutions and physical people that anything good they denounce, according to the European historical experience.

Palabras clave: Tutela judicial efectiva; derecho de defensa; tiempo judicial; errores judiciales; justicia y democracia.

Recepción original: 14/11/2013.

Aceptación original: 29/11/2013.

Key words: Effective protection of the court; right defense; procedural time: judicial errors; justice and democracy.

Sumario: I. Antecedentes. II. La Tutela Judicial: Una perspectiva territorial. II.1. Ámbito Estatal. II.2. Ámbito Regional Europeo. II.2.A. Unión Europea. II.2.A: a) Sistema Jurisdiccional Europeo. II.2.A: b) Carta de los Derechos Fundamentales de la Unión Europea (CDFUE). II.2.B. Consejo de Europa. II.2.B: a) Convenio Europeo de Derechos Humanos. II.2.B: b) Tribunal Europeo de Derechos Humanos. II.2.C. Encuentros y desencuentros. II.3. Ámbito Internacional. III. La Tutela Judicial Efectiva: Defensa, Proceso y Tiempo. III.1. El Derecho de Defensa. III.2. El Derecho a un proceso justo. III.3. El Derecho a que se resuelva el asunto planteado en un tiempo razonable. III.4. El Derecho a disponer de tiempo y de facilidades para defenderse. III.5. El Derecho a la autodefensa y a un defensor privado o de oficio. IV. Tutela Judicial, Derecho de Defensa y Tiempo Procesal. IV.1. La frialdad de los datos. IV.2. Tiempo Procesal. IV.3. Errores Judiciales. IV.4. Justicia y democracia. V. Conclusiones. VI. Corolario. VII. Bibliografía. 


\section{ANTECEDENTES}

Al enfrentar la Teoría de la Justicia con las infracciones y las sanciones legales justas e injustas, en el ámbito de la Tutela Judicial Efectiva, nos planteamos: ¿bajo qué circunstancias y hasta qué punto estamos obligados a obedecer normas injustas? La injusticia de una ley, no es, por lo general, una razón suficiente para incumplirla, como tampoco la validez legal de la legislación es una razón suficiente para aceptarla. Cuando la estructura básica de la sociedad es razonablemente justa, hay que reconocer que las leyes injustas son obligatorias siempre que no excedan ciertos límites de injusticia. Al tratar de distinguir estos límites, nos enfrentamos al problema del deber y de la obligación. La dificultad está en que en estos casos hay un conflicto de principios; unos, aconsejan la obediencia; otros, aconsejan lo contrario. Por tanto, las exigencias del deber y de la obligación han de ser examinadas a través de una concepción de prioridades previamente identificadas ${ }^{1}$.

En este entorno ¿cómo calificar, tanto la postura adoptada por la Generalidad Catalana al ignorar la parte declarada inconstitucional del Estatut de Catalunya ${ }^{2}$ como las reiteradas declaraciones del President de la Generalitat de Catalunya de convocar un referéndum pese a lo que digan las leyes o la Constitución Española ${ }^{3}$ ¿Es un caso de insumisión?

En el campo de la teoría del derecho, según Kelsen, lo que caracteriza a las normas es que el acto ilícito y la sanción están unidos por un vínculo del deber ser, lo que implica que si se produce un acto ilícito debe producirse una sanción En cambio, la ética o el derecho son disciplinas que se ocupan de las normas morales y de las normas jurídicas, basadas en el principio de imputación como criterio metodológico delimitador ${ }^{4}$. Kelsen sostiene que la única forma de distinguir entre el derecho y los otros órdenes normativos es por el tipo específico de sanción ${ }^{5}$.

1 RAWLS, John, Teoría de la Justicia, Madrid, Fondo de Cultura Económica, 1979, p. 391.

2 STC 31/2010, de 28 de junio (BOE núm. 172, de 16 de julio de 2010).

3 EL PAÍS (8 NOV 2012 - 20:43), SUBIRATS, Joan: «Mas o la personalización política». «El proceso electoral tiene todo el aspecto de convertirse en un debate entre Mas y las fuerzas políticas catalanas, incluyendo, en parte, a la misma coalición CiU. La estrategia de Mas fue quedando clara al anunciar el adelanto electoral y su promesa personal de salir del escenario político tras conseguir el objetivo de Estado propio. Es como poner todos los huevos en una única cesta...

4 CALSAMIGLIA, Albert, En defensa de Kelsen, Barcelona, Universitat Pompeu Fabra, 1997, Working Paper, 129.

5 «El sentido inmanente con el cual el legislador se dirige al órgano de aplicación de la Ley; éste a su vez, mediante la sentencia judicial o el acto administrativo, 
En la génesis histórica de toda ordenación jurídica se encuentran los conflictos de intereses individuales como experiencia vital de convivencia primitiva, que ha ido evolucionando desde la Autodefensa a la concepción actual de la Tutela Judicial Efectiva. Así, entendemos como conflicto de intereses la controversia surgida entre dos o más personas que mantienen posiciones antagónicas sobre un determinado bien, sea éste natural o cultural, apto para satisfacer necesidades o aspiraciones humanas. Desde esta óptica es posible concebir la experiencia jurídica como la resolución concreta de un conflicto humano de intereses contrapuestos ${ }^{6}$.

Buceando en las zonas más arcaicas de la vida humana organizada, en las viejas fórmulas sacramentales que inspiraron las legis actions y que derivaron en el ius civile del Derecho Romano ${ }^{7}$ o en el propio Código de Hammurabi, observamos que ya existían los Tribunales. Por ejemplo, la ley número 5, en uno de sus fragmentos dice: «Si un juez ha juzgado una causa, pronunciado sentencia (y) depositado el documento sellado, si, a continuación, cambia su decisión, se le probará que el juez cambió la sentencia que había dictado y pagará hasta doce veces la cuantía de lo que motivó la causa. Además, públicamente, se le hará levantar de su asiento de justicia (y) no volverá más $\left[\ldots . . . »^{8}\right.$

En este momento podríamos preguntarnos: ¿qué sería el Derecho sin la protección jurisdiccional, sin el Derecho a la Defensa? Sin lugar a dudas, no existirían relaciones jurídicas ni Derecho; HABRÍA PODER, PERO NO EL DERECHO QUE REGULA EL MUNDO OCCIDENTAL. Por ello hay que aceptar la HIPÓTESIS de que la evolución histórica de la solución de conflictos interpersonales pasa por diferentes etapas, dentro de cada una de las civilizaciones y culturas que han existido, pudiendo diferenciarse, aunque quizás con un excesivo reduccionismo, las tres fases siguientes: Autotutela no reglada, Autocomposición y la Heterocomposición, donde aparece el

al sujeto de derecho; el sujeto de derecho, en el negocio jurídico, a otro sujeto de derecho, no es captado con el enunciado relativo al curso probable de los acontecimientos». Fuente: Kelsen. Ibídem, p. 120.

6 DÍEZ-PICAZO, Luis, Experiencias jurídicas y teoría del derecho, 3. a edición, Barcelona, Ariel, 1999, pp. 10-11.

7 Antes de las XII Tablas (450 a. C.), el Derecho en Roma tenía un carácter religioso y su interpretación la realizaban sacerdotes que eran miembros de la clase patricia. Las protestas y agitaciones de la clase plebeya condujeron a que la ley consuetudinaria existente se escribiera añadiendo algunos principios que no formaban parte de la costumbre. Fuente: BCME, 2005.

8 El Código de Hammurabi es el primer cuerpo legal conocido de la historia. Fuente: BCME, 2005. 
Poder Judicial del Estado, con la pretensión de resolver el conflicto, prohibiendo a los particulares la Autodefensa, pero reconociendo el Derecho a la Defensa, como moderna forma democrática de solucionar un conflicto entre particulares.

Así, pues, el Derecho a la Defensa para la solución de los conflictos humanos pasa del estadio de la Autotutela a la posibilidad de recabar la protección jurisdiccional, evitando que los hombres se tomen la justicia por su mano, constituyéndose en la Esencia del Derecho. Pero esta evolución no ha sido simple. Para que la persona renuncie a la Autotutela, como estadio inicial del Derecho a la Defensa, necesitaba un PODER PÚBLICO que reconociera la TUTELA mediante un instrumento, la ACCIÓN, como derecho a reclamar su pretensión mediante un PROCESO, encaminado al fin perseguido. Con ello la ACCIÓN se convierte en un DERECHO PÚBLICO SUBJETIVO, ejercitable a través de la Judicatura (PODER ESTATAL) frente al otro litigante ${ }^{9}$. Así se configura inicialmente la TUTELA JUDICIAL, no discutiéndose si dicha Tutela es Genérica (DeclarativaTeoría Abstracta), o Concreta (Ejecutiva-Teoría Concreta) si tiene derecho a ella. Esta Tutela Judicial inicial, tras una larga evolución, dio contenido a los textos legales actuales (consuetudinarios o escritos), las modernas Constituciones, base constitutiva de los modernos Estados de Derecho y de los Tratados Internacionales sobre Derechos Humanos (DD.HH.).

En cuanto al PROCESO, como conjunto de actos encadenados unitariamente para alcanzar un fin $^{10}$, se inicia con el planteamiento de una PRETENSIÓN, se continúa con la PRUEBA DE LOS HECHOS aducidos, se referencian las NORMAS JURÍDICAS que favorecen a cada parte ${ }^{11}$ y se llega a la RESOLUCIÓN JUDICIAL, la SENTENCIA, punto culminante del proceso pero no el último,

9 La acción romana tuvo significados distintos en su tres fases de su procedimiento: a) durante las acciones de la ley, constituía la fórmula solemne con que los litigantes expresaban sus pretensiones [ ] Fuente: DEDU, Tomo 1, p. 72.

10 DRAE: proceso. (Del lat. processus). 1. m. Acción de ir hacia adelante. 2. m. Transcurso del tiempo. 3. m. Conjunto de las fases sucesivas de un fenómeno natural o de una operación artificial. 4. m. Der. Conjunto de actos y trámites seguidos ante un juez o tribunal, tendentes a dilucidar la justificación en derecho de una determinada pretensión entre partes y que concluye por resolución motivada. 5. m. Der. Causa criminal.

11 El derecho de acción, representa uno de los pilares fundamentales de la tutela judicial efectiva, aunque en ocasiones se confunde con otras instituciones jurídicas, como la pretensión y la demanda, que aunque parecidas e interrelacionadas sus funciones específicas dentro del ámbito procesal son distintas. Fuente: Montilla Bracho, Johanna H.: «La acción procesal y sus diferencias con la pretensión y demanda». Cuestiones Jurídicas, vol. II, núm. 2, julio-diciembre, 2008, pp. 89-110. 
puesto que da paso preceptivo al siguiente, la FASE EJECUTIVA, para restituir en sus justos términos la pretensión que dio inicio al proceso. En cualquier caso, conviene no confundir procedimiento con proceso. El procedimiento es la forma; y el proceso, el fondo ${ }^{12}$.

Finalmente, esta Tutela Judicial será INALCANZABLE O VACÍA DE CONTENIDO si no se concluye en tiempo razonable con la EJECUCIÓN DE LA SENTENCIA. De ahí que para que la Tutela Judicial se transformara en TUTELA JUDICIAL EFECTIVA, había que agregarle el calificativo que hiciera referencia a la efectividad, pues sin ésta la JUSTICIA SE HABRÍA CONVERTIDO EN UNA RETÓRICA VACÍA, SIN CONTENIDO DEMOCRÁTICO E INÚTIL PARA EL CIUDADANO $^{13}$. Es una percepción en que se expresa la cuestión de la legitimidad democrática de modo cada vez más acuciante. De ahí que, en el supuesto de la Unión Europea, los tratados de Maastricht, Amsterdam y Niza iniciaran la creciente incorporación del valor democrático al sistema institucional ${ }^{14}$.

De esta forma, LA JURISDICCIÓN, LA ACCIÓN Y EL PROCESO (EN SUS PERSPECTIVAS DE FORMA, FONDO Y TIEMPO) SE CONVIERTEN EN EL TRÍPODE QUE DA SOPORTE A LA TUTELA JUDICIAL, configurándose como elementos esenciales de la TUTELA JUDICIAL EFECTIVA, reconocidos por todos los ciudadanos para instar del PODER PÚBLICO la resolución de los CONFLICTOS INTERPERSONALES.

\section{LA TUTELA JUDICIAL: UNA PERSPECTIVA TERRITORIAL}

Aceptada la HIPÓTESIS de que la evolución histórica de la solución de conflictos interpersonales ha pasado por diferentes etapas, dentro de cada una de las civilizaciones y culturas que han existido, al plantearnos al alcance y significado de la TUTELA JUDICIAL, intentaremos extrapolar su proyección territorial en tres ámbitos distintos, pero complementarios y que se integran en una visión universal. Nos referimos a los ámbitos estatal, regional e internacional, pues su forma de identificarse implica numerosos matices que conviene diferenciar.

12 GARBERÍ LLOBREGAT, José, El derecho a la tutela judicial efectiva en la jurisprudencia del Tribunal Constitucional, Barcelona, Editorial Bosch, 2008. Pp. 11-27.

13 ZALBA: "El gran reto europeo es mejorar la legitimidad democrática». Fuente: http://www.diariofinanciero.com/ (13 de diciembre de 2012)

14 Se acepta el tópico que la «legitimidad democrática» es la menos mala de las formas de gobierno. 


\section{II.1 Ámbito Estatal}

En el Derecho Comparado Europeo el concepto de Tutela Judicial ha sido tratado escasa y desigualmente. Únicamente la Constitución italiana de 27-11-1947 habla de tal derecho en su artículo 24, afirmando también que la defensa es un derecho inviolable en cualquier momento del procedimiento. Además, su artículo 113 dispone que contra los actos de las Administraciones Públicas se admitirá siempre la Tutela Jurisdiccional de los derechos e intereses legítimos ante los organismos de la Jurisdicción Ordinaria o Administrativa.

Por su parte, el artículo 20.1 de la Constitución Portuguesa de 2-4-1976, dispone que se garantiza el acceso a los tribunales para la defensa, no pudiéndose denegar justicia a nadie por insuficiencia de recursos económicos. Dichas regulaciones, junto con el artículo 24 de la Constitución Española, no tienen correlato en otros países, pues las demás constituciones europeas no hacen referencia expresa al derecho a la tutela judicial efectiva ${ }^{15}$.

Estos derechos, también derivados del citado artículo y de la propia jurisprudencia del Tribunal Constitucional Español, son predicables no sólo del proceso penal, sino también de todos los demás procesos (civil, contencioso-administrativo, social, militar).

\section{II.2 Ámbito Regional Europeo}

En Europa contemplaremos dos ámbitos regionales, de significado diferente, pero judicialmente complementarios. Nos referimos a la Unión Europea (UE) y al Consejo de Europa (CdE), cada uno de los cuales tiene sus propias competencias, sus propios órganos y su propia organización.

\section{II.2.A Unión Europea}

Como se sabe, la UE es una ASOCIACIÓN POLÍTICO-ECONÓMICA que agrupa a 28 países europeos ${ }^{16}$, que cubren gran parte del Con-

15 MEJÍAS GÓMEZ, Juan Francisco La mediación como forma de tutela judicial efectiva, Madrid, El Derecho Editores, 2009, pp. 59-70.

16 Alemania (1952); Austria (1995); Bélgica (1952); Bulgaria (2007); Chipre (2004); Croacia (2013); Dinamarca (1973); Eslovaquia (2004); Eslovenia (2004); España (1986); Estonia (2004); Finlandia (1995); Francia (1952); Grecia (1981); Hungría (2004); Irlanda (1973); Italia (1952); Letonia (2004); Lituania (2004); Luxemburgo (1952); Malta (2004); Países Bajos (1952); Polonia (2004); Portugal (1986); Reino Unido (1973); República Checa (2004); Rumanía (2007); Suecia (1995). Fuente: http://europa.eu/about-eu/countries/index_es.htm. 
tinente, dotada de una serie de Instituciones, entre las que destacan el Parlamento, el Consejo Europeo y el Tribunal de Justicia, situando su génesis inicial en la Comunidad Económica Europea (CEE) creada mediante el Tratado de Roma (1957) suscrito inicialmente por seis países (Alemania, Bélgica, Francia, Italia, Luxemburgo y los Países Bajos), pero con vocación europeísta como nos demuestra su evolución posterior. La UE elabora sus propias normas jurídicas y sus propias leyes (reglamentos, directivas y decisiones).

El artículo 6 del TUE ${ }^{17}$ consagra la naturaleza de la Unión Europea (UE) como Estado de Derecho, lo que implica la existencia de un sistema jurídico, que dado su rápido desarrollo en ha convertido en una masa tan enorme de normas materiales como raquítico en garantías jurisdiccionales, lo que ha conllevado una cierta desorientación, un cierto distanciamiento, un cierto desprestigio del orden judicial, que se ha convertido en un problema, reprochable y achacable ${ }^{18}$ :

- En primer lugar, a los Estados partícipes del proyecto, en tanto que integrantes del «Legislador Comunitario» al que el Tribunal de Justicia remite las eventuales reformas.

- En segundo lugar, a la Jurisdicción Comunitaria, que no ha hecho aquí alarde de su capacidad creativa que tan fructífera ha sido para facilitar el proceso de integración económica, ni recurre al principio de Interpretación conforme ${ }^{19}$ que tan espléndidos resultados aportó en la transición jurídica.

- En tercer lugar, y parcialmente, a las Jurisdicciones Nacionales que siguen invocando la soberanía del juez para negar, injustificadamente y demasiadas veces, la consulta prejudicial.

Pero la afirmación de la UE como Estado de Derecho se vulnera cuando la articulación del sistema de atribución de potestades públicas no se corresponde con las garantías reconocidas a los ciudadanos frente al ejercicio de dichas potestades. No parece previsible un cambio de rumbo en este sentido, a pesar de las opiniones de los Abogados Generales del TJUE, Sr. Jacobs y Sr. Cosillas, del Juez del Tribunal de Primera Instancia Sr. Skouris o del anterior Defensor del Pueblo Europeo, Sr. Soderman ${ }^{20}$.

17 Artículo 6 TUE: Fuente: Versión Consolidada del Tratado de la Unión Europea. Diario Oficial n. ${ }^{\circ}$ C 83/19 de 30.3.2010.

18 GALERA RODRIGO, Susana., Sistema Europeo de Justicia Administrativa, Madrid, Dykinson, 2005, p. 262.

19 Principio que obliga a los jueces nacionales a interpretar el derecho interno a la luz del Derecho de la UE. En cuanto se refiere también a las directivas, es de gran trascendencia para nuestro Derecho, tanto Público -Derecho fiscal, social, adminsitrativo- como Privado -básicamente Derecho mercantil-. Su influencia puede alcanzar al Derecho Nacional. Fuente: Recopilación de Jurisprudencia 1990, p. I-04135.

20 GALERA RODRIGO, Susana, Ibídem, pp. 264-265. 


\section{II.2.A.a) Sistema Jurisdiccional Europeo ${ }^{21}$}

Al extender el contenido de la Tutela Judicial al ámbito de la Unión Europea, formada, como se dijo, por veintiocho Estados de Derecho $^{22}$, su valoración necesariamente ha de ser bien distinta, pues el acceso a la jurisdicción comunitaria de los particulares se regula subsidiariamente, reconociendo sólo a los Estados y a las Instituciones de la Unión el status de litigantes naturales. La tutela que los particulares reciben del Tribunal de Justicia de la Unión Europea $(\mathrm{TJUE})^{23}$ no permite los recursos personales directos de Anulación e Incumplimiento. Por ello es posible afirmar que «el Derecho Comunitario (NO) articula un completo sistema de vías de recurso», pues no tiene vigencia, según el propio Abogado General del TJUE, Sr. Jacobs $^{24}$.

Para garantizar el cumplimiento de la ley, su comprensión y una aplicación uniforme en todos los Estados miembros es indispensable una institución jurisdiccional, el Tribunal de Justicia de la Unión Europea (TJUE), integrado por tres órganos jurisdiccionales: el Tribunal de Justicia (creado en 1952), el Tribunal General (creado en 1988) y el Tribunal de la Función Pública (creado en 2004), constituyendo junto a los órganos jurisdiccionales de los EM, el Poder judicial de la Unión, con la finalidad de interpretar de modo uniforme el Derecho de la Unión y pronunciarse sobre su validez, respondiendo a las cuestiones planteadas por los órganos jurisdiccionales nacionales, los cuales desempeñan un papel fundamental, puesto que son quienes aplican el Derecho de la Unión, en primer lugar, junto con los tratados, reglamentos, directivas y decisiones del Derecho de la Unión.

El Sistema Jurisdiccional de la UE, manifiesta algunas debilidades ${ }^{25}$ :

21 http://europa.eu/about-eu/institutions-bodies/court-justice/index_es.htm

22 Ibídem.

23 El Tribunal de Justicia interpreta el Derecho de la UE y resuelve conflictos legales entre los gobiernos y las instituciones de la UE. Los particulares, las empresas y las organizaciones pueden acudir también al Tribunal si consideran que una institución de la UE ha vulnerado sus derechos. Fuente: http://europa.eu/about-eu/ institutions-bodies/court-justice/index_es.htm.

24 [...]100. La jurisprudencia sobre la legitimación de los particulares para interponer recurso ante el Tribunal de Justicia (en la actualidad ante el Tribunal de Primera Instancia) ha dado lugar, a lo largo de los años, a gran cantidad de comentarios, muchos de ellos muy críticos. Es innegable que la admisibilidad limitada de los recursos interpuestos por los particulares es considerada ampliamente como uno de los aspectos menos satisfactorios del ordenamiento jurídico comunitario [...]. Fuente: Conclusiones del Abogado General Jacobs presentadas el 21 de marzo de 2002.

25 Ibídem, pp. 6-8. 
- La más difundida es el restrictivo acceso directo de los ciudadanos a la jurisdicción comunitaria, a quienes se imponen unas condiciones procesales («afectación directa e individual») de acceso que lo hacen prácticamente impracticable más allá de unos pocos limitados $\operatorname{casos}^{26}$. Otra manifestación menos conocida de este déficit es la imposibilidad de reaccionar ante el Tribunal por parte de ciudadanos frente a incumplimientos del Derecho comunitario imputable a los Estados, acción de incumplimiento reservada a la Comisión y a los Estados.

- La segunda debilidad es la situación de indefensión que potencialmente se deriva de las denominadas actividades administrativas transnacionales; esto es, procedimientos administrativos de regulación comunitaria que se desarrollan en el territorio de varios Estados Miembros, normalmente con intervención de la Comisión ${ }^{27}$.

- La tercera debilidad apunta a la posibilidad de reaccionar frente a actos de la cada vez más numerosa Administración instrumental comunitaria, cuyo particularismo jurídico abarca también las eventuales vías de recurso que se puedan, o no, interponer frente a sus actos, llegándose a distinguir hasta tres grupos de posibilidades de recurrir sus actos en función de sus normas constitutivas ${ }^{28}$.

En consecuencia, y dada la dificultad de identificar y fijar el conjunto de principios comunes que configuran el Derecho de la Unión Europea $^{29}$, no habría que ir muy lejos para interpretar que sus crecientes referencias están afectando a los principios procedimentales generalmente reconocidos por los Estados Miembros (EM) ${ }^{30}$.

\section{II.2.A.b) Carta de los Derechos Fundamentales de la Unión Europea (CDFUE)}

El tradicional control jurisdiccional del TJUE ha sido notoriamente modificado por el Tratado de Lisboa (TL), que ha ampliado sus ámbitos materiales hasta cubrir el Derecho de la UE en su conjunto, salvo disposiciones contrarias de los Tratados; son recogidos en el artículo 19.3. del Tratado de la Unión Europea (TUE).

${ }^{26}$ En el marco de la Convención Europea, se señaló reiterada y contundentemente la necesidad de reparar esta situación. Ibídem, pp. 6-7.

$27 \quad$ A las dificultades de acceso a la jurisdicción comunitaria hay aquí que añadir la consideración de multitud de actos de instrucción, que ni siquiera han de notificarse a los interesados en el procedimiento... Fuente: Ibídem, p. 7.

28 El TL ha considerado la cuestión, aunque el artículo 263 TFUE extiende la acción de anulación a los actos de las «entidades, órganos y agencias de la Unión dirigidos a producir efectos jurídicos frente a terceros». Fuente: Ibídem, p. 8.

29 CHITI, M., "Forms of European administrative action, Law and Contemporary Problems», Vol. 68, 2004, p. 42.

30 CHITI, E., "Administrative proceedings involving European Agencies», Law and Contemporary Problems, Vol. 68, 2004, p. 227. 
La CDFUE incide en el derecho de los ciudadanos a una buena administración por parte de las Instituciones y Órganos de la UE, en los términos previstos en el artículo $41^{31}$.

Por otra parte, el reconocimiento de los Derechos Fundamentales por la UE puso de relieve que la Unión dejó de ser sólo un proyecto económico, pasando a constituirse en un proyecto más amplio. El Tratado de Ámsterdam ${ }^{32}$ modificó los Tratados constitutivos de la Comunidad, entre ellos el TUE, y dio lugar a un Espacio de Libertad, Seguridad y Justicia (ELSJ) ${ }^{33}$, con la pretensión de garantizar la libre circulación de personas, la prevención y lucha contra la delincuencia, desarrollando la cooperación judicial penal, el control de fronteras, la armonización de determinados tipos delictivos y la cooperación judicial civil. Los Derechos Fundamentales, tras una lenta evolución y merced a la labor creadora del TJUE, comprometido con los Derechos Humanos en proyección interior y exterior, se constituyen en una de las bases de la UE, apoyada en los principios de libertad, democracia, respeto a los derechos humanos y de las libertades fundamentales y el Estado de Derecho, principios comunes a todos los EM pertenecientes a la $\mathrm{UE}^{34}$.

Ahora bien, la construcción de un ordenamiento supranacional no implica la homogeneidad de derechos, ni la interpretación común por parte de diversas comunidades democráticas de naturaleza política, dotadas de mecanismos garantizadores de los mismos. En la estructura política de la UE, coexisten pluralidad de democracias constitucionales, por lo que a pesar de la pretensión limitadora de las cláusulas horizontales, la Carta puede reforzar el poder del TJUE en la interpretación de derechos, así como su capacidad de penetración en los ordenamientos estatales ${ }^{35}$.

31 Artículo 41. Derecho a una Buena Administración.

32 El Tratado de Amsterdam fue aprobado por el Consejo Europeo de Amsterdam (16 y 17 de junio de 1997) y firmado el 2 de octubre de 1997.

33 Al respeto, sl artículo 6.2 TUE afirma lo siguiente: «[...] 2. La Unión respetará los derechos fundamentales tal y como se garantizan en el Convenio Europeo para la Protección de los Derechos Humanos y de las Libertades Fundamentales firmado en Roma el 4 de noviembre de 1950, y tal y como resultan de las tradiciones constitucionales comunes a los Estados miembros como principios generales del Derecho comunitario.[...]». Fuente: Texto consolidado del TUE, de 7-2-1992, y modificado por el Tratado de Amsterdam (2-10-1997).

34 CALDERÓN CUADRADO, María Pía, e IGLESIAS BUHIGUES, José, El Espacio de Libertad, Seguridad y Justicia. Avances y Derechos Fundamentales en Materia Procesal, Navarra, Aranzadi, 2000, pp. 40-41.

35 Ibídem. 
La UE, por tanto, presta una especial atención a los Derechos Fundamentales y, por ende, al acceso a la Justicia. Para facilitar la cooperación judicial civil y penal, así como la circulación de sentencias, es necesario crear reglas comunes, armonizar las normas de conflicto y evitar aquellas situaciones en las que una persona pueda quedar privada del acceso a la Justicia ${ }^{36}$. Por esas y otras razones, el Tratado de Lisboa dota de naturaleza jurídica vinculante a la CDFUE, tras su largo proceso de elaboración ${ }^{37}$, una vez proclamada por el Consejo, la Comisión y el Parlamento Europeo el 7 de diciembre de 2000, aunque no introduce el texto completo de la Carta en los Tratados constitutivos, por la puerta grande, sino que la incorpora mediante el artículo 6 del TUE ${ }^{38}$ :

1. La Unión reconoce los derechos, libertades y principios enunciados en la Carta de los Derechos Fundamentales de la Unión Europea $^{39}$ de 7 de diciembre de 2000, tal como fue adaptada el 12 de diciembre de 2007 en Estrasburgo, la cual tendrá el mismo valor jurídico que los Tratados ${ }^{40}$. Las disposiciones de la Carta $^{41}$ no ampliarán en modo alguno las competencias de la Unión tal como se definen en los Trata$\operatorname{dos}^{42}$. Los derechos, libertades y principios enunciados en la Carta se interpretarán con arreglo a las disposiciones generales del título VII de la Carta por las que se rige su interpretación y aplicación y teniendo debidamente en cuenta las explicaciones a que se hace referencia en la Carta ${ }^{43}$, que indican las fuentes de dichas disposiciones.

2. La Unión se adherirá al Convenio Europeo para la Protección de los Derechos Humanos y de las Libertades Fundamentales ${ }^{44}$. Esta adhesión no modificará las competencias de la Unión que se definen en los Tratados ${ }^{45}$.

3. Los derechos fundamentales que garantiza el Convenio Europeo para la Protección de los Derechos Humanos y de las Libertades Fundamentales y los que son fruto de las tradiciones constitucionales comunes a los Estados miembros formarán parte del Derecho de la Unión como principios generales.

\footnotetext{
36 La CDFUE. Aida Torres Pérez. Barcelona, Universitat Pompeu Fabra, 27/28 de noviembre de 2008.

37 Sobre la CDFUE y su proceso de elaboración Fuente: Revue da Droit de l'Union européenne, n. ${ }^{\circ} 1$, pp. 27-65.

38 Antiguo artículo 6 TUE.

39 Protocolo 24 del TUE, relativo al asilo de nacionales.

40 Protocolo 8 del TUE, relativo a la adhesión al CEDH.

Protocolo 30 del TUE, relativo a la aplicación de la CDFUE a Polonia y Reino

42 Protocolo 8 del TUE, relativo a las competencias de la UE.

43 Protocolo 1 del TUE, relativo a la CDFUE.

44 Adopcióin TEDH por el CEDH, desde 1954.

45 Declaración 2 TUE sobre su artículo 6.
} Unido. 
Este precepto, como veremos a continuación, convierte a la Carta, versión de diciembre de $2007^{46}$, en el núcleo central del sistema de protección de los DFUE y la dota del mismo valor jurídico que los Tratados. La Carta se convierte así en Derecho Originario de la UE, aunque con la vitola de Derecho Derivado. ${ }^{47}$

\section{II.2.B. Consejo de Europa}

Hoy el Consejo de Europa ${ }^{48}$ es un sujeto internacional de carácter intergubernamental, que no ejerce control alguno sobre los Estados Parte (EP) (47 en el año 2012), los cuales, al integrarse en él, no ceden soberanía alguna. Entre sus creaciones destacan el Convenio Europeo de Derecho Humanos (CEDH) y el Tribunal Europeo de Derechos Humanos (TEDH), que se comentan en los epígrafes siguientes ${ }^{49}$.

\section{II.2.B.a) Convenio Europeo de Derechos Humanos}

El CEDH define y garantiza un mínimo de derechos comunes entre los países de tradición democrática, que se suelen conocer como Derechos Fundamentales de la Persona y que sucintamente descritos en el Protocolo $11^{50}$.

\section{II.2.B.b) Tribunal Europeo de Derechos Humanos}

Pasaron cuarenta y cinco años ${ }^{51}$ antes de que el CdE pusiera en marcha el TEDH como Órgano único de protección de los DD.HH.

${ }^{46}$ La versión finalmente adoptada de la Carta se publicó en el DOUE n. ${ }^{\circ}$ C 303 de 14 diciembre 2007.

47 CALDERÓN CUADRADO, María Pía e IGLESIAS BUHIGUES, José, Obra citada. P. 40.

48 Su origen hay que situarlo al final de la Segunda Guerra Mundial, en el llamado «Congreso Europeo» de los Estados de Benelux, Francia y el Reino Unido, que se celebró en La Haya entre el 7 y el 10 de mayo de 1948.

49 El Consejo de Europa es una organización internacional de ámbito regional destinada a promover la configuración de un espacio político y jurídico común en el continente, sustentado sobre los valores de la democracia, los derechos humanos y el Estado de Derecho. Constituido en el Congreso celebrado en La Haya el 7 de mayo de 1948 e integrado por países de origen plural. Fuente: Díez de Velasco, Manuel: Las Organizaciones Internacionales, Tecnos, Madrid, 2008, pp. 482-484.

50 El CEDH se firmó en Roma el 4-11-1950 y entró en vigor el 3-9-19534. Fuente: Secretaría del Tribunal Europeo de Derechos Humanos, Junio de 2010. Traducción española.

51 Los derechos humanos se establecieron en el Derecho internacional a partir de la II Guerra Mundial y en primer lugar, hay que citar la Declaración Universal de Derechos Humanos, aprobada por las Naciones Unidas el 10 de diciembre de 1948 [...]Fuente: BCME, 2005. 
reconocidos en la Convención de Roma y en sus Protocolos Adicionales. Fue el 1-11-1998 cuando entró en vigor el Protocolo Adicional número 11, firmado en Estrasburgo el 11-5-1994 ${ }^{52}$, superando la dualidad Comisión-Tribunal, iniciando el acceso al nuevo Tribunal tanto de los Estados como de cualquier persona física, organización no gubernamental o grupo de particulares víctimas de una violación de Derechos reconocidos por el CEDH o los Protocolos Adicionales (artículo 34 del Protocolo 11), aunque la Comisión continuó hasta el 31-10-99. Los criterios de legitimación activa anteriores se usan ahora frente al nuevo Tribunal (artículo 25 del CEDH) ${ }^{53}$.

En la actualidad, casi todos los Estados Parte (EP) han otorgado a sus ciudadanos el derecho a dirigirse al TEDH, derivando las demandas entabladas contra sus propios gobiernos. El número de Estados Parte (EP) firmantes del CEDH es superior al de los Estados Miembros (EM) de la UE. El Tribunal está compuesto por un juez de cada uno de los países miembros siendo un organismo permanente que se reúne durante todo el año en la ciudad francesa de Estrasburgo.

La jurisprudencia del TEDH es esencial en el sistema del Convenio de Roma, por cuanto que ha reinterpretado de tal modo los derechos reconocidos en el mismo que hoy no pueden interpretarse tales derechos como en el año 1950, cuando el CEDH fue firmado por los primeros Estados Parte (EP). Al respecto, se cita la reciente sentencia dictada por la Gran Sala del Tribunal Europeo de Derechos Humanos (TEDH) rechazando el recurso de España contra la condena que se le impuso por aplicar la conocida como doctrina Parot a la etarra Inés del Río. Esta sentencia, que puede suponer el fin de la citada doctrina Parot, abre la puerta a que otros presos con graves delitos a sus espaldas se acojan a ella, pues dicha decisión sobre la «Doctrina Parot» afecta a más de 150 presos que cumplen condena por terrorismo y otros graves delitos de asesinatos y violaciones. La sentencia ha establecido que la doctrina Parot, con la que se ha alargado la permanencia en prisión de decenas de etarras y otros condenados, no se puede aplicar por hechos cometidos antes de 1995. El Tribunal considera que lo contrario supone una aplicación retroactiva de la Ley y, por lo tanto, vulnera los derechos fundamentales de los presos, ignorando que tal doctrina no incide sobre la pena, que no se modifica, sino so-

52 Protocolo número 11 al CEDH relativo a la reestructuración del mecanismo de control establecido por el Convenio (Estrasburgo, 11 de mayo de 1994

53 DÍEZ DE VELASCO, Manuel, Las Organizaciones Internacionales, Madrid, Tecnos, 2008, pp. 481-500. 
bre la forma de computar la redención de penas, lo que forma parte de la Política Penitenciaria ${ }^{54}$.

La demanda ante el TEDH ha de interponerse cuando ya se han agotado las vías de recurso internas que el Estado pone a disposición del afectado en nuestro caso, la demanda ante la jurisdicción ordinaria y el amparo ante el $\mathrm{TC}^{55}$. Aunque ello implica también la posibilidad de conflictos entre éstos y el Tribunal de Estrasburgo, tal como ha ocurrido en la sentencia citada sobre la «Doctrina Parot», aunque normalmente la relación no es conflictual como las que se dan entre el Tribunal Supremo y el TC. El propio TC ha asumido la doctrina emanada del Tribunal de Estrasburgo en relación a determinados derechos fundamentales reconocidos tanto en la Constitución española como en el Convenio europeo y con especial trascendencia en las relaciones entre particulares ${ }^{56}$. Es el caso de los llamados «escraches ${ }^{57}$ », consistentes en ejercitar presiones violentas que atentan contra el derecho a la integridad física y moral, la intimidad personal y familiar de las personas, cualquiera que fuere su relevancia social $^{58}$, como por ejemplo, los practicados contra la Vicepresidenta del Gobierno, Soraya Sáenz de Santamaría en el centro de Madrid ${ }^{59}$ y contra la Juez Instructora Alaya (Eres de Andalucía ${ }^{60}$, Por tanto, la interpretación de los derechos reconocidos en el Convenio europeo que se hace en las sentencias del TEDH es fundamental para la pro-

54 «[... La doctrina Parot, establecida por el Tribunal Supremo en 2006 para que los delincuentes condenados por delitos graves pasen el tiempo máximo legal de estancia en prisión, que en el caso de Inés del Río eran 30 años. Dicha jurisprudencia obligaba a descontar los beneficios penitenciarios de cada una de las penas y no del máximo de cumplimiento efectivo. Sin embargo, el TEDH considera que vulnera el artículo 7 del Convenio Europeo de Derechos Humanos referidos al Derecho a la Libertad y a la seguridad y que infringe el artículo 7 referido a que no puede haber condenada si no existe ley previa. Fuente: ELMUNDO.es Actualizado lunes 21/10/2013 17:10 horas.

55 Artículo $35 \mathrm{CEDH}$.

56 MORTE GÓMEZ, Carmen, Cómo presentar una demanda ante el TEDH, tras la entrada en vigor del Protocolo n. ${ }^{\circ}$ 14, Valencia, Tirant lo Blanch, 2011, pp. 59-80.

57 DRAE. 1. tr. coloq. Arg. y Ur. Romper, destruir, aplastar.

58 STEDH de 9-12-1994, López Ostra c. España, como resulta de la línea jurisprudencial iniciada por la STC 119/2001, de 24 de mayo.

59 Un grupo de miembros de la Plataforma de Afectados por las Hipotecas (PAH), unos 200 según los testigos presenciales citados por Europa Press, se han concentrado este viernes por la tarde para hacer un escrache ante la vivienda de la número dos del Gobierno Español. Fuente: http://afectadosporlahipoteca.com

60 Un grupo de sindicalista se concentró ante el juzgado de la magistrada Mercedes Alaya, a la que recibieron con gritos y eslóganes como «!Alaya pepera, métete dentro de la lecheraj». Fuente: Diario LA GACETA, 7 de noviembre de 2013. Fuente: RTVE.ES (MADRID-05.04.2013) 
tección de los derechos fundamentales de la Constitución española tanto en el Derecho Público como en el Privado ${ }^{61}$.

\section{II.2.C. Encuentros y desencuentros}

La existencia en Europa de dos Organizaciones supranacionales: el Consejo de Europa (compuesto por cuarenta y siete PP) y la Unión Europea (compuesta por veintiocho PM), con sus respectivos Tribunales de Justicia (TEDH y TJUE), textos normativos diferentes que velan por la protección de los Derechos Humanos (CEDH y CDFUE), cuarenta y ocho constituciones de países europeos de los cuales veintiocho pertenecen a la Unión Europea, hacen muy complejo el análisis y discusión del alcance y significado de la Tutela Judicial en el ámbito de la Unión Europea, tanto por la materia, como por las competencias y por el distinto desarrollo de los dos Tribunales citados, donde se pueden identificar zonas convergentes de competencias, escasas situaciones de auténtico conflicto, inexistencia de una armonía absoluta y prevalencia de un respeto mutuo que ha creado un marco de cooperación frágil, aunque beneficiosa para ambas partes, pero insuficiente. Así lo pone de manifiesto la inadmisión a trámite por el TEDH de numerosos asuntos para evitar conflictos de competencia, con los efectos perversos que conlleva ignorar aquéllos que pueden provocar indefensión, y la carencia de la Tutela Judicial proclamada por los textos normativos diacrónicos del CdE y de la UE.

La inclusión de la CDFUE en el TL ha sido la oportunidad para que la UE se dotara de un marco propio que ayude a mantener esa cooperación beneficiosa en las relaciones entre ambas Cortes (TJUETJDH), como instrumento clarificador que despejara dudas sobre la existencia de un control del respeto a los DF en el ámbito de la UE. Esta comunicación deriva del actual Sistema Jurídico Europeo, entendido como el resultado de la interrelación permanente de ordenamientos jurídicos nacionales, supranacionales e internacionales, ordenados por un conjunto de reglas complicadas que buscan acoplar variados subsistemas en un sistema único que evite conflictos y contradicciones. En dicho contexto, las relaciones entre el CdE y la UE han sido buenas, aunque con encuentros y desencuentros recíprocos, desde el TEDH por la interpretación que haga del DUE, y desde el TJUE al interpretar el CEDH. En ambos casos, las soluciones dadas en uno y otro ámbito a determinados elementos esenciales

\footnotetext{
${ }^{61}$ Deriva del artículo 10.2 de la CE en relación a los artículos 32 y 46 del CEDH.
} 
del Estado de Derecho, en Europa no son equiparables. Una muestra sería la sentencia Bosphorus del TEDH, de 30-6-2005 ${ }^{62}$.

La UE, por tanto, presta una especial atención a los Derechos Fundamentales y, por ende, al acceso a la Justicia. Dada la preocupación existente en el seno de la Unión por el respeto de los Derechos Fundamentales, es natural su interés en evitar la posibilidad de que una persona quede privada de un derecho tan básico como el de acceso a la justicia por la existencia de diversidad de sistemas. Para facilitar la cooperación judicial civil y penal, así como la circulación de sentencias, es necesario crear reglas comunes, armonizar las normas de conflicto y evitar aquellas situaciones en las que una persona pueda quedar privada del acceso a la Justicia ${ }^{63}$. Por esas y otras razones, el Tratado de Lisboa dota de naturaleza jurídica vinculante a la CDFUE, tras su largo proceso de elaboración, una vez proclamada por el Consejo, la Comisión y el Parlamento Europeo el 7 de diciembre de 2000, aunque no introduce el texto completo de la Carta en los Tratados constitutivos, por la puerta grande, sino que la incorpora mediante el artículo 6 del TUE ${ }^{64}$ :

1. La Unión reconoce los derechos, libertades y principios enunciados en la Carta de los Derechos Fundamentales de la Unión Europea $^{65}$ de 7 de diciembre de 2000, tal como fue adaptada el 12 de diciembre de 2007 en Estrasburgo, la cual tendrá el mismo valor jurídico que los Tratados ${ }^{66}$. Las disposiciones de la Carta ${ }^{67}$ no ampliarán en modo alguno las competencias de la Unión tal como se definen en

62 La sentencia dictada por la Gran Sala del TEDH, de 30 de junio de 2005, en el asunto Bosphorus Airways c. Irlanda, tiene su origen en la demanda introducida en 1998 ante el TEDH por la compañía aérea turca Bosphorus Hava Yollari Turizm (Bosphorus Airways) contra Irlanda, por el apresamiento por parte de las autoridades irlandesas de un avión, que la demandante había alquilado a la compañía aérea yugoslava JAT, mientras éste se encontraba en territorio irlandés para llevar a cabo operaciones de mantenimiento, situación inicial resuelta por el Tribunal Irlandés mediante una cuestión prejudicial ante el TJUE, acerca de si el Reglamento comunitario era de aplicación en este caso, que éste resolvió de forma positiva. Esta sentencia abre un nuevo capítulo en las relaciones y la interacción entre el sistema europeo de protección de los derechos humanos y el sistema comunitario [...]. Fuente: Antón Guardiola, Carmen: STEDH. de 30-06-2005, Bosphorus Airways, 45036/98 - Derecho Comunitario y Convenio Europeo de Derechos Humanos. Revista de Derecho Comunitario Europeo ISSN 1138-4026, núm. 28. Madrid, septiembre-diciembre (2007). pp. 943-957.

63 La CDFUE. Aida Torres Pérez. Barcelona, Universitat Pompeu Fabra, 27/28 de Noviembre de 2008.

64 Antiguo artículo 6 TUE.

65 Protocolo 24 del TUE, relativo al asilo de nacionales.

66 Protocolo 8 del TUE, relativo a la adhesión al CEDH.

67 Protocolo 30 del TUE, relativo a la aplicación de la CDFUE a Polonia y Reino Unido. 
los Tratados ${ }^{68}$. Los derechos, libertades y principios enunciados en la Carta se interpretarán con arreglo a las disposiciones generales del título VII de la Carta por las que se rige su interpretación y aplicación y teniendo debidamente en cuenta las explicaciones a que se hace referencia en la Carta ${ }^{69}$, que indican las fuentes de dichas disposiciones.

2. La Unión se adherirá al Convenio Europeo para la Protección de los Derechos Humanos y de las Libertades Fundamentales ${ }^{70}$. Esta adhesión no modificará las competencias de la Unión que se definen en los Tratados ${ }^{71}$.

3. Los derechos fundamentales que garantiza el Convenio Europeo para la Protección de los Derechos Humanos y de las Libertades Fundamentales y los que son fruto de las tradiciones constitucionales comunes a los Estados miembros formarán parte del Derecho de la Unión como principios generales.

Este precepto convierte a la Carta de diciembre de $2007^{72}$, en el núcleo central del sistema de protección de los DFUE y la dota del mismo valor jurídico que los Tratados. La Carta se convierte así en Derecho Originario de la UE, aunque con la vitola de Derecho Derivado. ${ }^{73}$

De la lectura del artículo anterior se desprende una idea de la Carta como un catálogo flexible sobre el que ha de girar el Sistema de Protección de los DFUE, construido en torno a ella y a sus Explicaciones complementarias ${ }^{74}$, para seguir inspirándose en fuentes como el CEDH y las tradiciones constitucionales comunes de los EM, de tal forma que el artículo 6.3. pueda seguir siendo utilizado por el TJUE, de manera que determinados derechos no contemplados en la Carta se incorporen al catálogo de la UE por esta vía. Este planteamiento se enriquecerá con la adhesión de la UE al CEDH, tal y como prevé el artículo 6.2 TUE ${ }^{75}$.

En cualquier caso, en el DUE, la protección es más amplia que en el CEDH, pues el TJUE garantiza el derecho a un recurso efectivo ante

\footnotetext{
68 Protocolo 8 del TUE, relativo a las competencias de la UE.

69 Protocolo 1 del TUE, relativo a la CDFUE.

70 Adopcióin TEDH por el CEDH, desde 1954.

71 Declaración 2 TUE sobre su artículo 6.

72 La versión finalmente adoptada de la Carta se publicó en el DOUE n. ${ }^{\circ}$ C 303 de 14 diciembre 2007.

73 CALDERÓN CUADRADO, María Pía e IGLESIAS BUHIGUES, José. Obra citada. p. 40.

${ }^{74}$ Las Explicaciones fueron publicadas junto con la Carta en el DOUE n. ${ }^{\circ} \mathrm{C} 303$ de 14 diciembre 2007, y, según lo previsto en el artículo 6. 1 del futuro TUE deberán ser tenidas en cuenta en la interpretación de la Carta.

75 CALDERÓN CUADRADO, María Pía e IGLESIAS BUHIGUES, José. Obra citada p. 41.
} 
un juez, mediante su S15-5-86 (Johnston, asunto 222/84) ${ }^{76}$, principio que también se aplica a los EM cuando éstos aplican el DUE.

\section{II.3. Ámbito Internacional}

El Derecho Internacional clásico constituye la fuente de la protección moderna de los DD.HH., aunque su concepto se incorpora al argot diplomático en la Conferencia de San Francisco (1915) ${ }^{77}$. El moderno Derecho Internacional de los Derechos Humanos (DIDH)

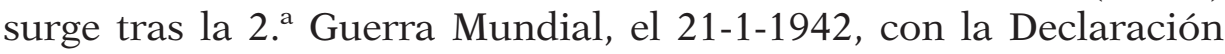
Naciones Unidas (DNU ${ }^{78}$ ), que sólo agrupaba a 26 Estados Aliados, subrayando que sólo una victoria completa sobre el enemigo era esencial "para defender tanto la vida, la libertad, la independencia y la libertad religiosa, como para conservar los Derechos Humanos y la Justicia en sus propios países y en los demás». En ese momento, alguna de las Potencias victoriosas tenía algún problema en el campo de los DD.HH., como la URSS, con sus gulag ${ }^{79}$; EE.UU. con la discriminación racial; Francia y Reino Unido con sus Imperios Coloniales ${ }^{80}$. No obstante, hay que asumir que la Carta de las Naciones Unidas $\left(\mathrm{CNU}^{81}\right)$ sienta las bases del futuro desarrollo de la

76 1) El principio de control jurisdiccional efectivo, consagrado por el artículo 6 de la Directiva 76/207 del Consejo, de 9-2-1976, se opone a que se otorgue el carácter de prueba irrefutable, que excluya toda posibilidad de control por un juez, a una certificación de una autoridad nacional en la que se afirme que se han cumplido las condiciones exigidas para autorizar una excepción al principio de igualdad de trato entre hombres y mujeres a fin de proteger la seguridad pública [...].

77 En la Conferencia de San Francisco, que elaboró la Carta de las Naciones Unidas, el 26 de junio de 1945, se propuso la adopción de una Declaración de los Derechos Humanos, que figuraría como anexo de la Carta, aunque limitada al articulado que hacía referencia a los Derechos Humanos.

${ }_{78}$ El 1 de enero de 1942, el presidente Roosevelt y los señores Winston Churchill, Maxim Litvinov, de la Unión Soviética, y T.V. Soong, de China, firmaron en Washington un documento que más tarde se conocería como la Declaración de las Naciones Unidas (DNU). Al día siguiente se sumaron los representantes de otras 22 naciones más. [...]». Fuente: http://www.segunda-guerra-mundial.com/2gm-declaracion-de-las-naciones-unidas.html.

79 Acrónimo de: Glavnoie Uptavlenie Laguerei. En español es: «Dirección General de Campos de Concentración URSS». La palabra gulag, escrita con minúscula inicial, se ha convertido en nombre común con el significado de «campo de concentración soviético». Fuente: http://www.fundeu.es/vademecum-G-gulag-338.html.

80 BOU, Valentín y CASTILLO, Mireya, Curso de Derecho Internacional de los Derechos Humanos, Valencia, Tirant lo Blanch, 2008, p. 44.

81 La Carta de las Naciones Unidas (CNU) se firmó el 26 de junio de 1945 en San Francisco, al terminar la Conferencia de las Naciones Unidas sobre Organización Internacional, y entró en vigor el 24 de octubre del mismo año. Fuente: http://www. un.org/es/documents/charter/intro.shtml 
protección internacional de los DD.HH. a través de su Preámbulo ${ }^{82}$ y sus artículos $1^{83}, 13^{84}, 55^{85}, 56^{86}, 62^{87}, 68^{88}$ y $76^{89}$.

\section{LA TUTELA JUDICIAL EFECTIVA: DEFENSA, PROCESO Y TIEMPO}

Superada la etapa del reconocimiento constitucional del derecho, de la separación de los poderes y de la reserva legal, al definirse el ámbito procesal frente a los poderes legislativo y ejecutivo, se concibió la Tutela Judicial Efectiva ${ }^{90}$ como garantía de los DD. HH. con el horizonte universal descrito en el siguiente Cuadro (n. $\left.{ }^{\circ} 1\right)$.

82 Preámbulo de la Carta Naciones Unidas (CNU). «[...]los Pueblos de las Naciones Unidas, resueltos a reafirmar la fe en los derechos fundamentales del hombre, en la dignidad y el valor de la persona humana, en la igualdad de derechos de hombres y mujeres[...]»

83 Artículo 1.3. CNU «[...] Realizar la cooperación internacional en el desarrollo y estímulo del respeto a los DD. HH. y a las libertades fundamentales de todos, sin hacer distinción por motivos de raza, sexo, idioma o religión[...]».

84 Artículo 13.1.b. CNU «[...] Fomentar la cooperación internacional y ayudar a hacer efectivos los Derechos Humanos y las libertades fundamentales de todos, sin hacer distinción por motivos de raza, sexo, idioma o religión[...]»

85 Artículo $55 \mathrm{CNU}$ «Con el propósito de crear las condiciones de estabilidad y bienestar necesarias para las relaciones pacificas y amistosas entre las naciones. la Organización promoverá:[...] c) e respeto universal a los Derechos Humanos y a las libertades fundamentales de todos, sin hacer distinción por motivos de raza, sexo, idioma o religión, y la efectividad de tales derechos y libertades».

86 Artículo 56. CNU «Todos los Miembros se comprometen a tomar medidas conjunta o separadamente, en cooperación con la Organización, para la realización de los propósitos consignados en el Artículo 55».

87 Artículo 62.2. MCNU «[...]2. El Consejo Económico y Social podrá hacer recomendaciones con el objeto de promover el respeto a los derechos humanos y a las libertades fundamentales de todos, y la efectividad de tales derechos y libertades.[...]»

88 Artículo 68: CNU «El Consejo Económico y Social establecerá comisiones de orden económico y social y para la promoción de los DD.HH. [...]»

89 Artículo 76.c) CNU «[...] promover el respeto de los Derechos Humanos y de las libertades fundamentales sin hacer distinción por motivos de raza, sexo, idioma o religión, así como el reconocimiento de la interdependencia de los pueblos del mundo.»

90 La Declaración Americana de los Derechos y Deberes del Hombre (Aprobada en la Novena Conferencia Internacional Americana Bogotá, Colombia, 1948), fue el primer acuerdo internacional, tomado seis meses antes que la Declaración Universal de los Derechos Humanos, aunque su valor jurídico ha sido discutido. Destaca su Artículo XVIII: Toda persona puede conocurrir a los tribunales para hacer valer sus derechos. Asimismo debe disponer de un procedimiento sencillo y breve por el cual la justicia lo ampare contra actos de la autoridad que violen, en perjuicio suyo, alguno de los derechos fundamentales consagrados constitucionalmente. 
DEMOCRACIA VERSUS TUTELA JUDICIAL, DERECHO A LA DEFENSA...

\section{CUADRO 1: SINOPSIS DE LA TUTELA JUDICIAL EFECTIVA DE LOS DD.HH.}

Fuente: Elaboración propia con datos procedentes de los textos institucionales citados

\begin{tabular}{|c|c|c|c|c|c|c|c|c|}
\hline $\begin{array}{l}\text { DERECHO A LA } \\
\text { TUTELA JUDICIAL } \\
\text { EFECTIVA }\end{array}$ & DUDH & PIDCP & $\mathrm{DADH}$ & $\mathrm{CADH}$ & $\mathrm{CAFDH}$ & $\mathrm{CEDH}$ & CDFUE & $\mathrm{CE}$ \\
\hline $\begin{array}{l}\text { Regulación genérica } \\
\text { de los derechos de las } \\
\text { personas en relación al } \\
\text { Poder Judicial }\end{array}$ & $\begin{array}{l}\text { Art } \\
8,11\end{array}$ & $\begin{array}{l}\text { Art } \\
2.3 ., 14\end{array}$ & $\begin{array}{l}\text { Art. } \\
\text { XVIII }\end{array}$ & $\begin{array}{l}\text { Art } \\
8,25\end{array}$ & & $\begin{array}{l}\text { Art } \\
6,13\end{array}$ & $\begin{array}{l}\text { Título } \\
\text { VI }\end{array}$ & Art.24 \\
\hline \multirow{2}{*}{\multicolumn{9}{|c|}{$\begin{array}{l}\text { INSTRUMENTOS COMPLEMENTARIOS INTERNACIONALES: } \\
\text { - Principios básicos relativos a la independencia de la judicatura. VII Congreso de } \\
\text { la ONU (Milán, 26-8/6-9-1985). } \\
\text { - Principios Básicos sobre la Función de los Abogados. VIII Congreso de las ONU } \\
\text { (Cuba, del 27-8/7-9-1990). } \\
\text { IBEROAMÉRICA: } \\
\text { - Código Iberoamericano Anexo III de la XIII Cumbre Judicial Iberoamericana } \\
\text { (junio } 2006 \text { - República Dominicana). } \\
\text { ESPANA: } \\
\text { - Carta de Derechos del Ciudadano ante la Justicia: Proposición no de Ley aproba- } \\
\text { da por el Congreso el día 16-4-2002. }\end{array}$}} \\
\hline & & & & & & & & \\
\hline \multicolumn{9}{|c|}{ DUDH: Declaración Universal de Derechos Humanos } \\
\hline \multicolumn{9}{|c|}{ PIDCP: Pacto Internacional de Derechos Civiles y Políticos } \\
\hline \multicolumn{9}{|c|}{ DADH: Declaración Americana de los Derechos y Deberes del Hombre } \\
\hline \multicolumn{9}{|c|}{ CADH: Convención Americana sobre Derechos Humanos } \\
\hline \multicolumn{9}{|c|}{ CAFDH: Carta Africana sobre Derechos Humanos y de los Pueblos } \\
\hline \multicolumn{9}{|c|}{$\begin{array}{l}\text { CEDH: Convenio para la Protección de los Derechos Humanos y de las Libertades } \\
\text { Fundamentales }\end{array}$} \\
\hline \multicolumn{9}{|c|}{ CDFUE: Carta de Derechos Fundamentales de la Unión Europea } \\
\hline \multicolumn{9}{|c|}{ CE: Constitución Española } \\
\hline \multicolumn{9}{|c|}{ PIDESC: Pacto Internacional de Derechos Económicos, Sociales y Culturales } \\
\hline CSE: Carta Social Eur & & & & & & & & \\
\hline
\end{tabular}

Con la finalidad de concretar nuestro proceso de análisis y discusión de la Tutela Judicial Efectiva como un Derecho fundamental ${ }^{91}$ dotado de un cierto garantismo, hay que determinar previamente su significado y alcance, lo que exige posicionarse previamente sobre la perspectiva teórica desde la cual hay que contemplarla, sea ésta la

91 En el presente epígrafe se toma como bibliografía básica de referencia la obra Carta de los Derechos Fundamentales de la Unión Europea. Comentario Artículo por Artículo. Dirigida por: Araceli Mangas Martín, Coordinada por: Luis N. González Alonso; con los colaboradores Manuel López Escudero; José Martín y Pérez de Nanclares y José Manuel Sobrino Heredia, especialmente en lo que concierne a los Artículo 47-54. Primera edición ISBN: 978-84-96515-80-2. Editorial Fundación BBVA, 2008. 933 páginas. 
concreta, la abstracta o la ecléctica. Entenderemos la tutela judicial efectiva como un derecho de configuración legal, siguiendo al TC español, tal como se manifiesta en el FJ 2. ${ }^{\circ}$, párrafo 2. ${ }^{\circ}$, de la Sentencia 228/2006, de 17 de julio, que nos dice:

«[...] El derecho a la tutela judicial efectiva es un derecho de prestación de configuración legal, por lo que su ejercicio y dispensación están supeditados a la concurrencia de los presupuestos y requisitos que en cada caso establezca el legislador, que, sin embargo, no puede, dado el carácter de derecho fundamental que tiene el que se ha invocado, fijar obstáculos o trabas arbitrarias o caprichosas (artículo 53.1 CE). [...]»

Desde este planteamiento entendemos que determinar su significado y alcance se puede intentar, pero siempre aunque con ciertas limitaciones, tras el análisis y discusión conjunta de los cuatro artículos (47, 48, 49 y 50) que forman el Título VI, de la CDFUE, dedicado a la Justicia, considerando las explicaciones originarias oficiales, así como el contenido del CEDH y las resoluciones del TJUE sobre la cuestión planteada.

Según el primer párrafo del artículo 47:

«Toda persona cuyos derechos y libertades garantizados por el Derecho de la Unión hayan sido violados tiene derecho a la tutela judicial efectiva respetando las condiciones establecidas en el presente artículo»

Dicha disposición se completa con el art. 19 del TUE, última frase de su primer apartado:

«Los Estados miembros establecerán las vías de recurso necesarias para garantizar la Tutela Judicial Efectiva en los ámbitos cubiertos por el Derecho de la Unión»

Además, los artículos 6.1 y 13 del CEDH ofrecen una cobertura más amplia, pues este derecho obliga tanto a la UE como a los EM.

- Artículo 6.1. CEDH. Toda persona tiene derecho a que su causa sea oída equitativa, públicamente y dentro de un plazo razonable, por un Tribunal independiente e imparcial, establecido por la ley, que decidirá los litigios sobre sus derechos y obligaciones de carácter civil o sobre el fundamento de cualquier acusación en materia penal dirigida contra ella. La sentencia debe ser pronunciada públicamente, pero el acceso a la sala de audiencia puede ser prohibido a la prensa y al público durante la totalidad o parte del proceso en interés de la moralidad, del orden público o de la seguridad nacional en una sociedad democrática, cuando los intereses de los menores o la protección de la vida privada de las partes en el proceso así lo exijan o en la medida en que será considerado estrictamente necesario por el Tribunal, cuando en circunstancias especiales la publicidad pudiera ser perjudicial para los intereses de la justicia. 
- Artículo 13 CEDH. Derecho a un recurso efectivo. Toda persona cuyos derechos y libertades reconocidos en el presente Convenio hayan sido violados, tiene derecho a la concesión de un recurso efectivo ante una instancia nacional, incluso cuando la violación haya sido cometida por personas que actúen en el ejercicio de sus funciones oficiales.

Como ha declarado el TJUE, entre los derechos fundamentales que la CDFUE protege, están los que conforman el derecho a la tutela judicial ${ }^{92}$ :

- Derecho a un juicio justo ${ }^{93}$

- Derecho a un tribunal independiente ${ }^{94}$.

- Derecho de defensa ${ }^{95}$.

- Decisiones motivadas ${ }^{96}$.

Desde una perspectiva integradora, el análisis y discusión que se hace sobre la Tutela Judicial Efectiva, como Derecho Fundamental, huye de cualquier teoría abstracta o concreta sobre dicho concepto, planteándolo como un derecho de contenido complejo, por lo que cualquier regulación que se haga del mismo no puede agotar sus posibilidades interpretativas. Para ello nos apoyaremos de manera concreta en el artículo 47 de la CDFUE:

Artículo 47. Derecho a la tutela judicial efectiva y a un juez imparcial

Toda persona cuyos derechos y libertades garantizados por el Derecho de la Unión hayan sido violados tiene derecho a la tutela judicial efectiva respetando las condiciones establecidas en el presente artículo.

Toda persona tiene derecho a que su causa sea oída equitativa y públicamente y dentro de un plazo razonable por un juez independiente e imparcial, establecido previamente por la ley. Toda persona podrá hacerse aconsejar, defender y representar.

Se prestará asistencia jurídica gratuita a quienes no dispongan de recursos suficientes siempre y cuando dicha asistencia sea necesaria para garantizar la efectividad del acceso a la justicia.

El Tribunal Constitucional Español, afirma que el artículo 24.1 CE no proclama el derecho de quienes acuden a los tribunales, a obtener de éstos un pronunciamiento favorable a sus pretensiones, ni tampoco secunda la teoría abstracta de la Tutela Judicial Efec-

92 Galera Rodrigo, Susana: Sistema Europeo de Justicia Administrativa, Obra citada, p. 131.

93 STJUE, de 17-12-98, As. C-185/93.

94 STJUE, 11-1/2000, As. 35/67.

95 STJUE, 15-11-68 As. 35/67.

96 STJUE, 15-10-87, As. 222/86. 
tiva (SSTC 50/1997, 9/2005, 308/2006, 132/2007, 9/1981, 52/1992, 20/1987, entre otras) de manera que el Derecho Fundamental a la Tutela Judicial Efectiva, según el Alto Tribunal, tiene los siguientes contenidos esenciales ${ }^{97}$ :

1. El derecho de acceso a la jurisdicción

2. El derecho a obtener de los tribunales un pronunciamiento fundado en el Derecho objetivo, que será de fondo cuando concurran todos los presupuestos procesales, observando los requisitos de la motivación y la congruencia.

3. El derecho a los recursos que las leyes establezcan contra las resoluciones judiciales.

4. El derecho a la ejecución de las resoluciones judiciales.

5. El derecho a la inmodificabilidad de las resoluciones judiciales firmes fuera de los cauces legalmente establecidos al efecto.

6. Y el derecho a no sufrir indefensión en el proceso.»

\section{III.1 El Derecho de Defensa}

Según el artículo 48.2 de la CDFUE: «se garantiza a todo acusado el respeto de los derechos de la defensa». El artículo 6.3 del CEDH, desarrolla dicho artículo, enumerando los siguientes contenidos, como exigencias procesales sin carácter limitativo:

1. a ser informado, en el más breve plazo, en una lengua que comprenda, y detalladamente, de la naturaleza y de la causa de la acusación formulada contra él;

2. a disponer del tiempo y de las facilidades necesarias para la preparación de su defensa;

3. a defenderse por sí mismo o a ser asistido por un defensor de su elección y, si no tiene medios para pagarlo, a poder ser asistido gratuitamente por un abogado de oficio, cuando los intereses de la justicia lo exijan;

4. a interrogar o hacer interrogar a los testigos que declaren contra él y a obtener la citación y el interrogatorio de los testigos que declaren en su favor en las mismas condiciones que los testigos que lo hagan en su contra; $y$

5. a ser asistido gratuitamente por un intérprete, si no comprende o no habla la lengua empleada en la audiencia.»

97 GARBERÍ LLOBREGAT, José, El Derecho a la Tutela Judicial Efectiva en la Jurisprudencia del TC, Barcelona, Bosch, 2008, pp. 18-19. 
Ahora bien, para que este derecho sea algo más que una especulación, y adquiera eficacia jurídica, es necesario contar con un soporte legal que implique ${ }^{98}$ :

- El reconocimiento del derecho a la tutela judicial con un contenido que suponga una limitación sustancial a la libertad del legislador en el momento en que dicta las leyes ordinarias que establecen requisitos para el ejercicio de aquel derecho.

- La previsión de medios específicos de protección del contenido con el que el derecho a la tutela judicial aparece constitucionalmente reconocido, de modo que sea posible hacerlo prevalecer frente a normas e, incluso, frente a actos jurídicos que pudieran desconocerlo.

Al contemplar el ámbito europeo en un entorno mundial hay que resituarse en la singularidad internacional que ha supuesto la creación de la Unión Europea, que ha configurado un sistema jurídico atípico, fragmentado en sus orígenes, multinivel en su perspectiva, inacabado en su construcción, en el que se puede apreciar la interacción que se ha dado entre tres sistemas jurídicos, como se dijo: el constitucional de los países miembros; el comunitario, que nace y se desarrolla en sus Tratados, su propia legislación y la jurisprudencia creadora del TJUE (fundada en las tradiciones jurídicas comunes de los Estados Miembros de la Unión Europea) y del CEDH, procedente del Consejo de Europa.

\section{III.2 El Derecho a un proceso justo}

Este derecho se concreta en el segundo párrafo del artículo 47 de la CDFUE, constituyéndose en el primer derecho que favorece la Tutela Judicial Efectiva:

«[...] Toda persona tiene derecho a que su causa sea oída equitativa y públicamente y dentro de un plazo razonable por un juez independiente e imparcial, establecido previamente por la ley. Toda persona podrá hacerse aconsejar, defender y representar. [...]»

La regulación del Proceso tiene alcance general, incluyendo todos los ámbitos procesales, también el contencioso-administrativo, desbordando los límites establecidos en el artículo 6.1 del CEDH, aunque dentro del ámbito de aplicación regulado en el artículo 51. de la CDFUE.

1. Las disposiciones de la presente Carta están dirigidas a las instituciones, órganos y organismos de la Unión, dentro del respeto

98 ORTELLS RAMOS, Manuel, AA. VV, Introducción al Derecho Procesal, Navarra, Aranzadi, 2010, pp. 249-255. 
del principio de subsidiariedad, así como a los Estados miembros únicamente cuando apliquen el Derecho de la Unión Por consiguiente, éstos respetarán los derechos, observarán los principios y promoverán su aplicación, con arreglo a sus respectivas competencias y dentro de los límites de las competencias que los Tratados atribuyen a la Unión.

2. La presente Carta no amplía el ámbito de aplicación del Derecho de la Unión más allá de las competencias de la Unión, ni crea ninguna competencia o misión nuevas para la Unión, ni modifica las competencias y misiones definidas en los Tratados.

\section{III.3 El Derecho a que se resuelva el asunto planteado en un tiempo razonable}

La celeridad del procedimiento es otra garantía que comprende el derecho a un juicio justo, cuya traducción es la obligación de que el tribunal resuelva el asunto en un plazo razonable. El carácter razonable de tal plazo debe apreciarse en función de las circunstancias propias de cada asunto y, en particular, de la trascendencia del litigio para el interesado, de la complejidad del asunto, del comportamiento del demandante y de la actuación de las autoridades competentes.

\section{III.4 El Derecho a disponer de tiempo y de facilidades para defenderse}

El demandado tiene derecho a defenderse con los medios adecuados, como se deriva del artículo 6.3.b. del CEDH: «a disponer del tiempo y de las facilidades necesarias para la preparación de su defensa». El acusado ha de disponer del tiempo y facilidades que necesite para la preparación de su defensa, lo que permite al TEDH controlar las condiciones en las que se desarrolla, valorando el tiempo del que ha dispuesto letrado para entrevistarse con su cliente, el plazo disponible para la preparación del asunto, la recogida de los documentos de prueba, etc., con el fin de evitar una defensa meramente aparente.

\section{III.5 El Derecho a la autodefensa y a un defensor privado o de oficio}

Especialmente significativo resulta el tenor literal del artículo 6.3.c) del CEDH que permite: «[...] defenderse por sí mismo o a ser asistido por un defensor de su elección y, si no tiene medios para pagarlo, a poder ser asistido gratuitamente por un abogado de oficio, cuando los intereses de la justicia lo exijan», pues reconoce el derecho de autodefenderse o de ser asistido por un defensor. 
El TJUE se ha referido a este derecho, afirmando que figura entre los derechos fundamentales que se desprenden de las tradiciones constitucionales comunes a los Estados miembros (TJUE, sentencia de 28-3-2000, Krombach, C-7/98, ap. 38).

\section{TUTELA JUDICIAL, DERECHO DE DEFENSA Y TIEMPO PROCESAL}

Para el TJUE, según su INFORME ANUAL 2010, dicho año fue de consolidación de las reformas introducidas en el sistema jurisdiccional de la Unión mediante el Tratado de Lisboa. El procedimiento para ejecutar la más importante de dichas reformas, a saber, la adhesión de la UE al CEDH, se inició este mismo año. El TJUE ha seguido y continuará siguiendo de cerca la evolución de la aplicación de dicho procedimiento».

2010 marcará los anales por la eficacia y el ritmo particularmente sostenido de la actividad judicial de la institución. Cabe destacar, a este respecto, que se ha interpuesto un total de 1.406 asuntos ante los tres órganos jurisdiccionales que componen el TJUE, lo que representa la cifra más elevada en la historia de la institución y demuestra el aumento constante del volumen del contencioso de la UE. Además, merece igualmente ser reseñada la disminución global de la duración de los procedimientos, disminución harto significativa concretamente en los asuntos prejudiciales.

Finalmente, el año transcurrido vio también partir a dos Miembros y al Secretario del Tribunal de Justicia, así como a cuatro Miembros del Tribunal General, partida que se inscribe en el marco de su renovación parcial. A este respecto, es preciso señalar que los nombramientos de los nuevos Miembros del Tribunal de Justicia y del Tribunal General son los primeros que se producen en el marco del nuevo procedimiento introducido por el TL, tras un dictamen del comité previsto en el artículo 255 TFUE.

En resumen, el Informe ofrece una presentación completa de la evolución y la actividad de la Institución durante el año 2010. Como cada año, se dedica una parte sustancial del Informe a las exposiciones sucintas pero exhaustivas de la actividad jurisdiccional propiamente dicha del Tribunal de Justicia, del Tribunal General y del Tribunal de la Función Pública. El análisis de dicha actividad du- 
rante el año 2010 viene completado e ilustrado por datos estadísticos específicos de cada órgano jurisdiccional.» ${ }^{99}$

\section{IV.1 La frialdad de los datos}

\section{CUADRO 2: TRIBUNAL DE JUSTICIA. EVOLUCIÓN \\ DE LA ACTIVIDAD JUDICIAL (1952-2010)}

Fuente: Elaboración propia con datos del Informe anual 2010 del TJUE

\begin{tabular}{|c|c|c|c|c|c|c|c|c|}
\hline Año & $\begin{array}{c}\text { Recur- } \\
\text { sos } \\
\text { direc- } \\
\text { tos }\end{array}$ & $\begin{array}{c}\text { Cuestio- } \\
\text { nes } \\
\text { prejudi- } \\
\text { ciales }\end{array}$ & $\begin{array}{c}\text { Recur- } \\
\text { sos de } \\
\text { casa- } \\
\text { ción }\end{array}$ & $\begin{array}{c}\text { Recursos } \\
\text { de casación } \\
\text { medidas } \\
\text { provisionales o } \\
\text { demandas } \\
\text { de intervención }\end{array}$ & $\begin{array}{c}\text { Solicitu- } \\
\text { des } \\
\text { de dictá- } \\
\text { menes }\end{array}$ & Total & $\begin{array}{c}\text { Deman- } \\
\text { das de } \\
\text { medi- } \\
\text { das pro- } \\
\text { visiona- } \\
\text { les }\end{array}$ & $\begin{array}{c}\text { Senten- } \\
\text { cias / } \\
\text { Dictáme- } \\
\text { nes }\end{array}$ \\
\hline Total & 8.601 & 7.005 & 1.118 & 85 & 19 & 16.828 & 351 & 8.637 \\
\hline
\end{tabular}

CUADRO 3: ACTIVIDAD JUDICIAL POR INCUMPLIMIENTO

DE ESTADOS MIEMBROS (1952-2010)

Recursos iniciados: Fuente: Elaboración propia con datos del Informe anual 2010 del TJUE

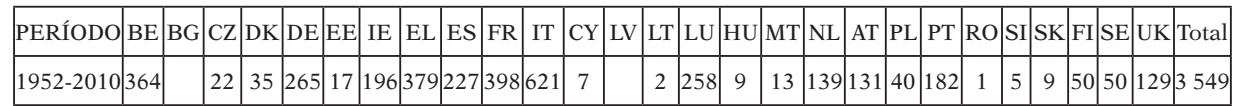

El Tribunal de Justicia terminó 522 asuntos en 2010 (cifra neta, teniendo en cuenta las acumulaciones) lo que representa una ligera disminución respecto del año anterior (543 asuntos terminados en 2009). De ellos, 370 concluyeron con una sentencia y 152 dieron lugar a un auto.

En 2010, se sometieron al Tribunal de Justicia 631 asuntos nuevos (con independencia de las acumulaciones por razón de conexión), lo que representa un aumento considerable respecto del año 2009 (562 asuntos) y constituye el número de asuntos interpuestos más elevado en la historia del Tribunal de Justicia. Idéntica situación presentan las peticiones de decisión prejudicial. El número de asuntos prejudiciales interpuestos este año es, por segundo año consecutivo, el más alto jamás alcanzado y, en comparación con el año 2009, registra un aumento del 27,4 \% (385 asuntos en 2010 frente a 302 asuntos en 2009).

99 INFORME ANUAL 2010: Resumen de las actividades del Tribunal de Justicia, del Tribunal General y del Tribunal de la Función Pública de la Unión Europea. Luxemburgo 2011. Fuente: www.curia.europa.eu.. 
Por último, el TJ ha utilizado frecuentemente la posibilidad, abierta por el artículo 20 de su Estatuto, de juzgar sin conclusiones del Abogado General cuando el asunto no plantee ninguna cuestión de Derecho nueva. Cabe señalar que alrededor de un $50 \%$ de las sentencias dictadas en 2010 se pronunciaron sin conclusiones (frente a un $52 \%$ en 2009).

Si la UE tiene una superficie de 4 millones de $\mathrm{km}^{2}$ y una población de 503 millones de habitantes, es evidente que el volumen de asuntos tratados son imperceptibles e irrelevantes para el Ciudadano Europeo ${ }^{100}$.

\section{IV.2 Tiempo procesal}

CUADRO 4: DURACIÓN DE LOS PROCEDIMIENTOS TERMINADOS (20062010) ${ }^{101}$

Fuente: Elaboración propia con datos del Informe anual 2010 del TJUE

\begin{tabular}{|c|l|r|r|r|r|r|}
\hline ÓRGANO & \multicolumn{1}{|c|}{ ACTIVIDAD } & 2006 & 2007 & 2008 & 2009 & 2010 \\
\hline \multirow{4}{*}{ JJ } & Cuestiones prejudiciales & 19,8 & 19,3 & 16,8 & 17,1 & 16,1 \\
\cline { 2 - 7 } & $\begin{array}{l}\text { Procedimientos prejudiciales de } \\
\text { urgencia }\end{array}$ & 2,5 & S/D & 2,1 & 2,5 & 2,1 \\
\cline { 2 - 7 } & Recursos directos & 20 & 18,2 & 16,9 & 17,1 & 16,7 \\
\cline { 2 - 7 } & Recursos de casación & 17,8 & 17,8 & 18,4 & 15,4 & 14,3 \\
\hline \multirow{5}{*}{ TG } & Ayudas de Estado & 29,0 & 32,4 & 48,1 & 50,3 & 32,4 \\
\cline { 2 - 7 } & Competencia & 41,1 & 42,6 & 40,2 & 46,2 & 45,7 \\
\cline { 2 - 7 } & Función pública & 24,8 & 32,7 & 38,6 & 52,8 & \\
\cline { 2 - 7 } & Propiedad intelectual & 21,8 & 24,5 & 20,4 & 20,1 & 20,6 \\
\cline { 2 - 7 } & Otros recursos directos & 24,2 & 21,5 & 20,6 & 23,9 & 23,7 \\
\cline { 2 - 7 } & Recursos de casación & & 7,1 & 16,1 & 16,1 & 16,6 \\
\hline \multirow{2}{*}{ TFP } & Sentencias & & & & & 25,1 \\
\cline { 2 - 7 } & Autos & & & & & 11,5 \\
\hline
\end{tabular}

La importancia que tiene el tiempo procesal en la valoración de un sistema jurisdiccional vigente en un Estado Social y Democrático de Derecho, puede clarificarse, en el caso de España, en tres casos que por su significado y trascendencia jurídico-política son ejemplarizantes, pues como se dice en términos vulgares, el transcurso del

\footnotetext{
100 Fuente: http://europa.eu/about-eu/facts-figures/living/index_es.htm.

101 En sentencias y autor de carácter jurisdiccional.
} 
tiempo devalúa el sentido de la Justicia. Nos referiremos a los casos de «Rumasa ${ }^{102}$ », «Doctrina $\operatorname{Parot}^{103}$ » $\mathrm{y}$ «El caso faisán ${ }^{104}$ »

\section{IV.3 Errores judiciales}

La posibilidad de que los jueces se equivoquen en sus decisiones es un hecho aceptado en los sistemas jurídicos modernos, a pesar de la cadena de revisiones existentes para subsanar los errores que pudiera cometer el juez inferior. En España no existe una definición legislativa de error judicial, mientras entre la jurisprudencia y la doctrina no existe unanimidad, ni es una cuestión pacífica. Literalmente, el artículo 121 de la Constitución española dice: «Los daños causados por error judicial, así como los que sean consecuencia del funcionamiento anormal de la Administración de Justicia, darán derecho a una indemnización a cargo del Estado, conforme a la Ley». En el desarrollo de dicho Art., la LOPJ de 1985 regula sucintamente esta institución en sus artículos 292 a $297^{105}$.

102 Larga batalla judicial del caso del holding Rumasa, el imperio económico de José María Ruiz Mateos, que fue expropiado por el gobierno de Felipe González hace ahora 28 años. El grupo empresarial contaba entonces con 65.000 trabajadores, 700 empresas y 18 bancos. La decisión la tomó el recién estrenado gobierno socialista. La batalla judicial se ha prolongado durante años. El Tribunal Constitucional y Supremo avalaron tanto la expropiación como las reprivatizaciones. Pero Ruiz Mateos también obtuvo victorias. La Audiencia Nacional le absolvió de los delitos de falsedad y el Tribunal de Estrasburgo reconoció su indemnización. Fuente: www.rtve.es, la 1 , Telediario, 17/02/2011.

103 El 10 de julio de 2012 condenando a España por aplicar la «doctrina Parot» a la etarra Inés del Río. España recurrió ante la Gran Sala de ese Tribunal y el día 1-10-2013 se conoció su sentencia. Según el Tribunal de Estrasburgo se ha vulnerado el principio de legalidad al aplicar a hechos anteriores un criterio novedoso y más perjudicial sobre el cumplimiento de penas, lo que viola el artículo 7 del Convenio de Roma que prevé que nadie puede ser condenado por un hecho que, en el momento de cometerlo, no sea delito ni puede imponerse una pena más grave que la prevista en el momento de delinquir. [...]. Por tanto, cuando desde el Gobierno se dice que habrá que aplicarla caso a caso dice una obviedad: no habrá una salida masiva, en tropel, pero sí una aplicación generalizada a todos a los que se les haya denegado la libertad en virtud de la «doctrina Parot», hayan acudido o no a Estrasburgo. Fuente: José Luis Requero-Magistrado de la Audiencia Nacional. La Razón21-10-2013-Sentencia Estrasburgo.

104 El PP ha presentado un recurso de casación ante el TS por la sentencia del caso del chivatazo, que condenó al exjefe superior de Policía en el País Vasco Enrique Pamiés y al inspector José María Ballesteros a un año y medio de cárcel por el soplo a ETA en el bar Faisán el 4 de mayo de 2006, según han informado a Europa Press fuentes "populares". En concreto, la Audiencia Nacional condenó a año y medio de cárcel y cuatro [...]». Fuente: Europa Press - jue, 24 oct 2013

105 Malem Seña, J. F: El error judicial y la formación de los jueces, Gedisa, Barcelona, 2008, pp. 195-207. 
En el periodo 2006-2010 se procesaron 160 expedientes por motivo de errores judiciales, lo que arroja una media de 32 presos inocentes por año. En el caso de los ciudadanos detenidos por error (prisión preventiva), la cifra sube hasta los 1.116 expedientes tramitados. Al respeto, en 2010 se registraron en España casi 9,5 millones de asuntos, la mayoría de los cuales era de orden penal (6,6 millones). Según datos facilitados por el Consejo General del Poder Judicial, se dictaron 1.686 .425 sentencias, que dieron lugar a 2.379 escritos de reclamaciones por disconformidad con la resolución judicial (un 14\% del total de escritos de reclamaciones, denuncias, sugerencias y peticiones de información recibidos). En ese contexto, el Ministerio de Justicia tramitó 331 expedientes de presos inocentes y de ciudadanos privados de libertad por errores u omisiones judiciales, 14 órdenes de captura, 288 prisiones preventivas y 29 casos de prisión, calificados como errores judiciales. El gobierno español indemnizó por valor de medio millón de euros, cifra muy superior a la registrada en 2009 y que triplica a la de 2008, cuando tuvo que hacer frente al pago de más de 167.000 euros, repartidos entre seis expedientes. De los 647 expedientes de responsabilidad patrimonial iniciados en 2010, se resolvieron 466. De ellos, un 12,8\% fueron estimados, quedando un total de 181 sin resolver. En los últimos cinco años se ha estimado un 14\% del total de expedientes resueltos. «En delitos muy personales como una agresión sexual o un abuso, la víctima a veces reconoce a alguien erróneamente, sin maldad. Psicológicamente, necesita ponerle cara a un culpable[...]» ${ }^{106}$.

\section{CUADRO 5. EXPEDIENTES DE RESPONSABILIDAD INICIADOS (2006- 2010)}

Fuente: (Ministerior de Justicia) según el ICAV. El Legajo. Segunda etapa, n. ${ }^{\circ} 21,2 .^{\circ}$ trimestre 2011. Págs. 5-11)

\begin{tabular}{|c|c|c|c|c|}
\hline AÑO & TOTAL & INADECUADOS $^{1}$ & $\begin{array}{c}\text { PRISIÓN } \\
\text { PREVENTIVA }\end{array}$ & ERRÓNEOS \\
\hline 2006 & 620 & 436 & 170 & 14 \\
\hline 2007 & 490 & 267 & 198 & 25 \\
\hline 2008 & 556 & 293 & 221 & 42 \\
\hline 2009 & 613 & 324 & 239 & 50 \\
\hline 2010 & 647 & 330 & 288 & 29 \\
\hline
\end{tabular}

106 ICAV: Errores judiciales cuando el sistema falla. El Legajo, 2. ${ }^{a}$ etapa, n. ${ }^{\circ} 21$, 2. ${ }^{\circ}$ trimestre 2011, pp. 5-11. 


\section{IV.4 Justicia y democracia}

El déficit democrático de la Unión Europea ${ }^{107}$ invoca principalmente la inaccesibilidad de la UE al ciudadano por la complejidad del funcionamiento de La Unión ${ }^{108}$. Aunque los tratados de Maastricht, Amsterdam y Niza iniciaron la creciente incorporación de dicho principio democrático al sistema institucional ${ }^{109}$, la institución nacida de esa preocupación, por su origen y capacidad de decidir, el Parlamento Europeo, tiene escasa relevancia en la Gobernanza de la Unión Europea, pues deciden los Estados, no los Ciudadanos.

La vía a la justicia y la sujeción del poder público al control jurisdiccional son percibidos inmediatamente por el ciudadano como elementos de prestigio y de querencia de sus instituciones. Un déficit en estos elementos, conlleva una devaluación de las instituciones y cierto desapego del ciudadano, ante lo que hay que reaccionar, pues del desprestigio institucional nada bueno ha resultado según demuestra la larga historia europea, y como evidencia el cuadro número $1^{110}$.

Siendo la Tutela Judicial Efectiva el elemento esencial de la vida democrática y la más visible de las instituciones, sorprende esa desafección en aumento entre los ciudadanos europeos y sus instituciones, según datos publicados por el Eurobarómetro, como podemos apreciar en el Cuadro 6: «Seulement une minorité des citoyens des Vingt-sept déclarent avoir confiance dans leur justice (43\%), un pourcentage en recul de 5 points par rapport au printemps 2009».

\section{Ibídem.}

108 Zalba: "El gran reto europeo es mejorar la legitimidad democrática» Desde la Comisión de Asuntos Monetarios del Parlamento Europeo, su vicepresidente Pablo Zalba se muestra convencido de que el acuerdo sobre el supervisor bancario es un paso «irreversible» e «importantísimo». Además, apuesta por la imparcialidad de Draghi y señala que el BCE no es la institución más opaca del viejo continente. Fuente: http://www.diariofinanciero.com/ (13 de Diciembre de 2012)

109 Sin entrar en planteamientos doctrinales de corte ideológico, ni polémicas marginales al sentido del presente trabajo, de una forma laxa, se puede aceptar que la «legitimidad democrática» se basa en el convencimiento en la población de que la democracia es la menos mala de las formas de gobierno, independientemente de la opinión que se tenga sobre el desempeño del gobierno determinadas decisiones, puesto que existe alternacia en el poder y votaciones a través de la cual se manifiesta la opinión de los ciudadanos.

110 Eurobaromètre Standard 72. Automne 2009. L'opinion Publique dans l'Union Europeenne. Volume 1. Étude réalisée par TNS Opinion \& Social à la demande de la Commission européenne-Direction générale Communication. Coordonnée par la Commission européenne-Direction générale Communication. TNS Opinion \& Social. Rapport Terrain: octobre-novembre 2009. Publication: février 2010, p. 122. 
Este desprestigio del orden judicial, entraña riesgos políticos, como manifestó Ortega y Gasset al afirmar que: «fascismo y cesarismo tienen, como supuesto común, el previo desprestigio de las instituciones[...] situación en que, efectivamente, a un puñado de hombres les es fácil adueñarse del poder público: cuando éste es res nullius, cuando el resto del cuerpo social no se siente solidario de él, cuando nadie estima las instituciones vigentes» ${ }^{111}$.

Es también elocuente con relación a este tema, el siguiente comentario del periódico El Mundo: Telefónica hizo pública su renuncia a hacerse con el control de Vivo, compañía líder en Brasil de telefonía móvil. La empresa española retira su oferta sobre el 50\% de Brasilcel, accionista mayoritaria de Vivo, paquete que está en posesión de Portugal Telecom. La decisión de Telefónica es la consecuencia de la actitud del Gobierno portugués, que ha burlado las leyes comunitarias. Portugal ha vulnerado el principio de libertad de circulación de capitales y nadie le ha obligado a cumplir la legalidad vigente. La Comisión Europea se ha limitado a repudiar su actuación sin tomar ninguna medida. Flagrante demostración de cómo un país puede incumplir la legislación comunitaria sin ninguna consecuencia. Clara dejación de la UE, que ha permitido un precedente que muy pronto se volverá en su contra ${ }^{112}$.

Frente a este problema nos planteamos la conveniencia de conocer cuáles son los rasgos comunes, las características de las «tres patas básicas» que deben orientar cualquier Sistema Jurisdiccional Justo, como son el Derecho de Defensa, la Tutela Judicial Efectiva y el Tiempo Judicial, cuestión no resuelta por la Filosofía ni por la Teoría del Derecho, dado el pragmatismo con que se ha orientado la armonización judicial europea, mediante especificaciones materiales mínimas, lo que resulta manifiestamente insuficiente ${ }^{113}$.

111 ORTEGA Y GASSET, J., Sobre el fascismo. El Espectador, 2. ${ }^{a}$ edición, Madrid, «Biblioteca Edaf», 2004, p. 110. Citado por Galera Rodrigo, Susana: Sistema europeo de justicia administrativa, Dykinson, Madrid, 2005, p. 265.

112 Editorial de El Mundo, titulado: Cuando la UE permite que se atropelle a Telefónica. Publicado el domingo, 18 de julio de 2010, p. 3.

113 TIEDEMANN, Klaus,: Requisitos fundamentales de una regulación de la Parte General del Derecho Penal, Munich, Carl Heymanns, 2001. Ha contribuido, en forma especial, al desarrollo de las teorías de responsabilidad penal de las personas jurídicas, además de aportar sus conocimientos al estudio de las leyes penales en blanco, resaltando especialmente las dificultades que tales técnicas presentan para el funcionamiento del ordenamiento comunitario europeo. Fuente: Revista Electrónica del lnstituto Latinoamericano de Estudios en Ciencias Penales y Criminología. ILECIP. E. 02-KT (2006). http://www.ilecip.org/pdf/Ilecip.Ent.2006-02.pdf. 


\section{CUADRO 6: GRÁFICO ESTADÍSTICO DE LA CONFIANZA EN LA JUSTICIA \\ DE LA UE, 2009}

Fuente: Eurobaromètre Standard 72. Automne 2009

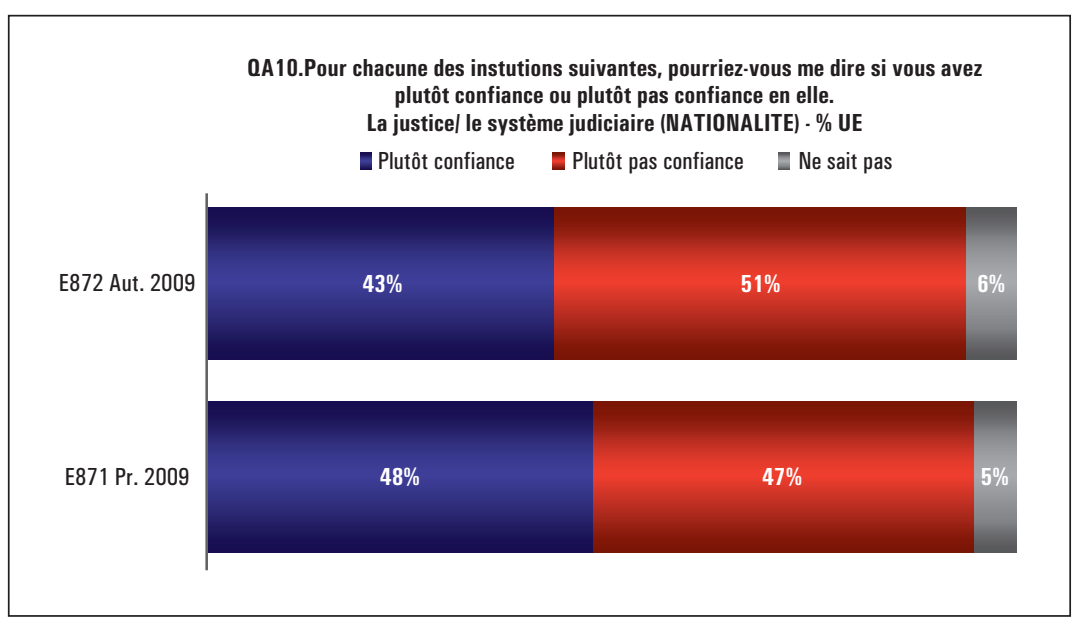

En España, se puede citar como síntoma de la creciente desafección popular hacia las instituciones judiciales, las numerosas manifestaciones públicas orquestadas contra los Tribunales españoles, Constitucional y Supremo, derivadas del polémico Estatuto de Cataluña, simiente autogerminativa de sentimientos separatistas ${ }^{114}$; de la inhabilitación del Magistrado de la Audiencia Nacional, Don Baltasar Garzón, de las protestas generalizadas de los indignados del $15 \mathrm{M}$, tomando lugares públicos; del antiguo asunto denominado «caso Faisán, consistente en un «soplo» a la ETA sobre una redada policial, recientemente sentenciado bajo el principio de que «el fin justifica los medios» ${ }^{115}$; y de las presiones sindicalistas contra la Juez Anaya en el asunto de los ERE's andaluces.

114 «El problema de Cataluña, y lo demás son retóricas, es la deslealtad de sus gobernantes con el pacto constituyente; todos, los que hace más de treinta años han urdido los mimbres para educar torcidamente a más de una generación y los que hoy quebrantan sistemáticamente lo que prometieron al acceder a las instituciones que administran»... Y además es imposible. Federico Ysart, Editorial ABC 18-10-2013, PÁG. 3.

115 «BALANCE DESOLADOR DEL CASO FAISÁN. La sentencia del caso Faisán «resulta desalentadora para quienes confían en el Estado de Derecho como la única vía admisible para derrotar a ETA». El chivatazo «buscaba torpedear la acción judicial y poner a los terroristas fuera del alcance de sus compañeros policías». Pero «para los magistrados de la Audiencia Nacional esto no es colaboración con banda armada, porque los dos policías querían favorecer el fin de ETA, no su actividad terrorista». Este razonamiento "se asienta en un relativismo ético y legal inaceptable cuando se trata de acabar con la delincuencia terrorista». "No tiene lógica que los magistrados firmantes de esta sentencia ignoren que el resultado concreto del chiva- 
Recientemente, en España, el Juez de la Audiencia Nacional, D. Baltasar Garzón, se encontraba en suspensión de empleo y sueldo decretada por el CGPJ, por estar imputado en tres juicios derivados de varias querellas admitidas a trámite ${ }^{116}$, una de las cuales derivó de la autorización del citado Juez para el desenterramiento de hipotéticos cadáveres procedentes de la Guerra Civil Española. Este hecho circunstancial nos sitúa frente al debate doctrinal sobre la subsistencia de los actos políticos no sometidos a control jurisdiccional ${ }^{117}$. Se observa una creciente intensidad en la actuación de los gobiernos en determinados casos de gran sensibilidad política, acentuada a raíz del atentado terrorista del 11 de septiembre de 2001 (Torres Gemelas de EE.UU.), en un entorno cada vez más globalizado y conflictivo, que ha multiplicado ciertas actuaciones políticas incidiendo en la esfera jurídica civil, desencadenando una gran demanda de tutela judicial de los ciudadanos frente a dichas actuaciones, hasta el punto que se ha propiciado el rescate del debate sobre los límites del control judicial respecto de determinadas actos políticos o de gobierno.

Con ello, la historia de la judialización de las cuestiones políticas o actos de gobierno aparenta una evolución estrictamente jurídica que opera en el plano de la ciencia, olvidando que toda categoría científica no se puede descontextualizar históricamente ni tampoco impedir su uso por parte de una comunidad determinada. Tras el

tazo fue el favorecimiento directo e inequívoco a unos terroristas». Fuente: ABC, 18 de octubre de 2013, pág. 5, Editorial».

116 La Sala Penal del Tribunal Supremo decide por unanimidad, el 26 de mayo de 2009, abrir un proceso al juez Garzón por un delito de prevaricación durante la instrucción de la causa por las desapariciones del franquismo. El 12 de mayo, se ordena finalmente, en sede judicial, la apertura del juicio oral por un presunto delito de prevaricación intencionada, y no por una prevaricación meramente imprudente. Una vez dictada la apertura de juicio oral, el CGPJ convoca un pleno extraordinario el viernes 14 de mayo en el que decide la suspensión cautelar del magistrado de la Audiencia Nacional. El 28 de enero de 2010, también por unanimidad, el Supremo abre una causa por presuntos delitos de prevaricación y cohecho por el dinero que solicitó personalmente y recibió del entonces BSCH, BBVA, Cepsa, Endesa y Telefónica para financiar actividades que desarrolló durante su estancia en la Universidad de Nueva York en 2005 y 2006. El 24 de febrero de 2010 la Sala Penal del Supremo abre la tercera causa por presuntos delitos de prevaricación por autorizar las escuchas de las conversaciones que mantuvieron en prisión los imputados en el "caso Gürtel" con sus abogados defensores. El 11 de abril de 2011, se ordenó la apertura de juicio oral del caso de las escuchas, al que siguió el del del franquismo, para finalizar el juicio sobre cohecho.

117 El Secretario General del PSOE, Felipe González, en relación con la desclasificación de los papeles del Cesid (1986), afirmó ayer que «las decisiones políticas de los Gobiernos no son revisables por los jueces, porque si lo fueran eso sería el gobierno de los jueces, del que a veces se habla». Fuente: Enric Company, Barcelona, 14/10/1996. Citado por: ELPAIS.com, Edición impresa, España. Viernes, 3/2/2012. 
largo camino jurídico recorrido, nos encontramos, básicamente, con dos perspectivas de la intervención de Poder Juridicial en la Vida Política, que describimos a continuación ${ }^{118}$ :

a) Restrictiva. Esta concepción pretende limitar el control judicial sobre los asuntos de gobierno para impedir el llamado «gobierno de los jueces» ${ }^{119}$ a efectos de mantener el equilibrio de la división de poderes y de evitar que un poder quede a merced de otro, como consecuencia de la judicialización del poder político.

b) Maximalista. Este planteamiento somete en su totalidad las cuestiones políticas al control judicial, porque parte del hecho que de lo contrario nos encontraremos con una judicatura sometida a los poderes ejecutivo y legislativo, con la consiguiente debilitación de la tutela judicial efectiva de las personas.

En cualquier caso, en la realidad actual no cabe la dualidad anterior, sino que hay que considerarla como los límites entre los cuales se sitúan las modernas democracias occidentales. En los países de nuestro entorno o de cultura jurídica similar, se diversifican los casos que se pueden dar al replantearse las viejas doctrinas sobre la cuestión comentada. A título de ejemplo se pueden citar ${ }^{120}$ :

- Reino Unido: Reclamación causada por daños derivados de detención ilegal y torturas en la que se pide la desclasificación de documentos enmarcados en el proceso judicial correspondiente, a la que se oponía el Ministerio de Exteriores, pero que finalmente, mediante Sentencia de la Corte Civil de Apelación, de 10 de febrero de 2010, sí concede dicha clasificación

- Italia: Decisión judicial del Tribunal de Casación italiano de 8 de febrero de 2002 que declaraba a los tribunales internos incompetentes para examinar la demanda de indemnización de daños y perjuicios en aplicación del Código civil italiano, por actos de guerra y políticos del gobierno, como consecuencia de un ataque aéreo de las fuerzas de la OTAN en el que el gobierno italiano tuvo una participación determinante.

- EE.UU. Decisión desestimatoria sobre el control judicial de actividades calificadas como secretos de Estado y relacionadas con la seguridad nacional en el marco de una demanda de daños derivados de torturas y otros tratos crueles y degradantes (Novena Corte de Apelación de Estados Unidos de 21 de abril de 2009).

118 CASSAGNE, Juan C., Derecho Administrativo, Tomo II, Lima, Palestra Editores, 2010, pp. 155-178.

119 Al respecto, Lambert, Edouard, afirma que: «el inmenso poder político que poseen los tribunales norteamericanos conduce a proclamar la existencia de un real "gobierno de los jueces» como también de una verdadera oligarquía judicial». Fuente: Cassagne, Juan Carlos: Derecho administrativo, Tomo II. Obra citada, 155-178.

120 GALERA RODRIGO, Susana, "Consejo de Europa y Unión Europea ¿complementariedad o superposición?", Obra citada, p. 9-10. 
- España: Frente a un Acuerdo de Consejo de Ministros denegando una solicitud de extradición, el TS ${ }^{121}$ manifestó que se debía cursar la solicitud; asimismo, el mismo Tribunal declaró la improcedencia de la inadmisión a trámite dictada por el Ministerio del Interior, de una solicitud de asilo ${ }^{122}$; asimismo, el TS estimó el recurso contra el traslado de la sede de la Comisión del Mercado de las Telecomunicaciones (CMT) a Barcelona interpuesto por la Comunidad Autónoma de Madrid y por los representantes de los trabajadores de este órgano regulador, enmarcando la decisión en el ámbito de la potestad organizativa aunque en los votos particulares se subraya el ejercicio de acto político ${ }^{123124}$.

- Consejo de Europa: El CdeE admite la exclusión relativa de la fiscalización judicial de las decisiones políticas fundamentales del Estado. ${ }^{125}$

- Unión Europea: Esta cuestión no se ha suscitado en dicho marco, pues las actividades propias de esta categoría han estado excluidas del funcionamiento de las instituciones comunitarias, hasta el Tratado de Lisboa, supuestos dados en el segundo (Política Exterior y de Seguridad Común) y tercer pilar (Cooperación Judicial y Policial en materia Penal) ${ }^{126}$.

\section{CONCLUSIONES}

El derecho a la tutela judicial constituye la base fundamental del Estado de Derecho, soportado constitucionalmente (justicia, seguridad jurídica, legalidad, etc.) y articula las garantías individuales subyacentes en los procesos jurisdiccionales.

Así, pues, el acceso a la Justicia, avalado por la existencia de una Tutela Judicial Efectiva a título personal y de un Control Jurisdiccional sobre las Administraciones Públicas son manifestaciones de la escala de valores que sustenta al moderno Estado Social y Democrático de Derecho y son percibidas por la Sociedad Civil como factores constitutivos de su legitimación política, de tal forma que cuando dichas manifestaciones se deprecian socialmente, se produce un dis-

121 STS 31-5-2005.

122 STS 14-12-2006.

123 STS 27-11-2006.

124 GARCÍA DE ENTERRÍA, Eduardo y FERNÁNDEZ, Tomás Ramón, Curso de Derecho administrativo, Tomo II. 14. a, Navarra, Thomson-Civitas, 2008. pp. 582-587.

125 STEDH de 21-9-1994, Fayed c. Reino Unido, párrafo 65. Citado por Galera Rodrigo, Susana: «Consejo de Europa y Union Europea: ¿complementariedad o superposición?», Obra citada, p. 11.

126 GALERA RODRIGO, Susana, Consejo de Europa y Unión Europea: ¿complementariedad o superposición?. Obra citada, p. 11-12.. 
tanciamiento entre las Instituciones y las personas físicas, que nada bueno presagian, según la histórica experiencia europea.

Desde la óptica del derecho constitucional, consideramos relevante comentar y cuestionar la Sentencia de 23 de enero de 2004, dictada por la Sala de lo Civil del Tribunal Supremo, en la que se condenó a once Magistrados del Tribunal Constitucional al pago de una indemnización de 500 euros al demandante en amparo (Abogado en el ejercicio de la profesión), por la inadmisión de una demanda de amparo. Con ella se ha conmocionado el inestable equilibrio de las máximas instituciones jurisdiccionales sin base en una reflexión jurídica seria. La resolución pedida por el recurrente caía fuera de las competencias del TC y además iba dirigida a un Tribunal cuya abstención se había solicitado con carácter previo. El problema central está, no en saber si el Alto Tribunal actuó de forma correcta o no lo hizo así, sino en establecer quién es competente para decidirlo.

$\mathrm{Y}$, en estos momentos de crisis económica, política e institucional, la consecuencia es un creciente desapego entre los ciudadanos y la Justicia, tal como se aprecia, a título ejemplarizante, desde el propio Palacio de la Zarzuela (EL MUNDO, 23-6-2013, pág. 1), a raíz de los recientes abucheos a los Príncipes de España en el Liceo de Barcelona y a la Reina Sofía en el Auditorio Nacional de Madrid, al atribuirlos la Casa del Rey a la «reacción de la calle contra el Poder, no contra la Monarquía». Para corregir esta situación es necesario que la Tutela Judicial Efectiva se exprese con la Justicia en una mano y las máximas garantías procesales en la otra.

\section{COROLARIO}

El logro de una Zona Europea de la Justicia debe consolidarse para superar la fragmentación actual del Sistema Jurídico de la Unión Europea. Debería darse prioridad a los mecanismos destinados a facilitar el acceso a la justicia, de modo que las personas puedan hacer valer sus derechos en toda la Unión. Es necesario también mejorar la cooperación entre los profesionales del Derecho, así como su formación, y movilizar recursos para poner fin a los obstáculos al reconocimiento de los actos jurídicos en otros Estados Miembros, de acuerdo con el objetivo de alcanzar «Una Europa de la Ley y la Justicia», tal como lo establece el PROGRAMA DE ESTOCOLMO ${ }^{127}$.

127 Plan estratégico quinquenal, presentado conjuntamente por la Presidencia sueca del Consejo y por la Comisión Europea, y adoptado por el Consejo Europeo, en 2009, con el ámbito de aplicación está diseñado entre 2010 y 2015, para incre- 


\section{BIBLIOGRAFÍA}

TORRES PÉREZ, Aida: CDFUE, Barcelona, Universitat Pompeu Fabra, 27/28 de Noviembre de 2008.

BCME, Biblioteca de Consulta Microsoft Encarta, 2005.

BOU FRANCH, Valentín y CERVERA VALLTERRA, María: Normativa y jurisprudencia básica del derecho de la Unión Europea, Tirant lo Blanch, Valencia, 2010

BOU FRANCH, Valentín y CASTILLO DAUDÍ, Mireya: Curso De Derecho Internacional de Los Derechos Humanos, Tirant lo Blanch, Valencia, 2008.

CALDERÓN CUADRADO, María Pía y IGLESIAS BUHIGUES, José Luis: El espacio europeo de libertad, seguridad y justicia. Avances y derechos fundamentales en materia procesal, Aranzadi, Camino de Galar, 15, Cizur Menor (Navarra), 2009.

CALSAMIGLIA, A.: En defensa de Kelsen, Universitat Pompeu Fabra, Working Paper 129, Barcelona, 1997.

CAPELLA, Juan-Ramón: El Derecho Como Lenguaje, Ariel, Barcelona 1968.

CASSAGNE, Juan C.: Derecho Administrativo, Tomo II, Palestra Editores. Lima, 2010, pp. 155-178.

CHICHARRO LÁZARO, Alicia: Tratado de Lisboa y el programa de Estocolmo: Los nuevos retos de la cooperación judicial en materia civil, Revista Electrónica de Estudios Internacionales, Número 20, diciembre 2010.

CHITI, E. «Administrative proceedings involving European Agencies», Law and Contemporary Problems, Vol. 68, 2004.

CHITI, M. «Forms of European administrative action, Law and Contemporary Problems», Vol. 68, 2004.

CHITI, M. Pietro: Derecho Administrativo Europeo, Aranzadi, Cno. de Galar, 15, Cizur Menor (Navarra), 2002.

DEDU, Diccionario Enciclopédico de Derecho Usual.

mentar y consolidar la seguridad en el interior del territorio de la UE. Este programa marca las principales metas a conseguir en relación con el espacio judicial europeo para los próximos cinco años. Fuente: Alicia Chicharro Lázaro, Tratado de Lisboa y el programa de Estocolmo: Los nuevos retos de la cooperación judicial en materia civil, Revista Electrónica de Estudios Internacionales, Número 20, diciembre 2010. 
DÍEZ DE VELASCO, Manuel: Instituciones de Derecho Internacio-

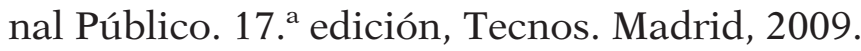

DÍEZ DE VELASCO, Manuel: Las Organizaciones Internacionales. 15. a edición, Tecnos, Madrid, 2008.

DÍEZ MORENO, Fernando: Manual de Derecho de la Unión Europea. 5. ${ }^{a}$ edición, Aranzadi, Camino de Galar, 15, Cizur Menor (Navarra), 2009.

DÍEZ-PICAZO, Luis: Experiencias jurídicas y Teoría del Derecho, 3. ${ }^{\mathrm{a}}$ edición, Ariel, Madrid, 1999.

DRAE. Diccionario de la Lengua Española

EINSTEIN, Albert: Mis ideas y opiniones, Bosch, Barcelona, 1980.

ELÍAS MÉNDEZ, C., «La jurisdicción constitucional en los Estados miembros de la Unión Europea», Revista de Derecho Constitucional Europeo, núm. 16, julio-diciembre 2011, ps. 17-52.

ELÍAS MÉNDEZ, C., «Aproximación a la Sentencia del Tribunal Constitucional sobre el Estatuto de Autonomía de Cataluña: nación, lengua, derechos y competencias», Revista General de Derecho Constitucional, núm. 10, octubre 2010.

ELÍAS MÉNDEZ, C., The participation of the German Länder and of the Spanish Autonomous Communities in the European Union: a Comparative Analysis, en A. López Basaguren and L. Escajedo San-Epifanio (eds.), The Ways of Federalism in Western Countries and the Horizons of Territorial Autonomy in Spain, Vol. 1, Springer-Verlag Berlin Heidelberg 2013.

Enciclopedia Jurídica. La Ley. Madrid, 2008-2009.

Eurobaromètre Standard 72. Automne 2009. L"opinion Publique dans l"Union Europeenne. Volume 1. Étude réalisée par TNS Opinion \& Social à la demande de la Commission européenne-Direction générale Communication. Coordonnée par la Commission européenneDirection générale Communication. TNS Opinion \& Social. Rapport Terrain: octobre-novembre 2009. Publication: février 2010.

GALERA RODRIGO, Susana: La aplicación administrativa del Derecho Comunitario. Administración Mixta, tercera vía de aplicación, Cívicas, Madrid 1998.

GALERA RODRIGO, Susana: Sistema Europeo de Justicia Administrativa, Dykinson, Madrid, 2005. 
GARBERÍ LLOBREGAT, José: El derecho a la tutela judicial efectiva en la jurisprudencia del Tribunal Constitucional, Editorial Bosch, Barcelona, 2008. Garberí Llobregat, José; Morenilla Allard, Pablo: Convenio europeo de Derechos Humanos y jurisprudencia del Tribunal Europeo relativa a España: textos, protocolos, nuevo reglamento del Tribunal, normas complementarias de demanda, Bosch, Barcelona, 1999.

GARCÍA DE ENTERRÍA, Eduardo; TIZZANO, Antonio; ALONSO GARCÍA, Ricardo: Código de la UE, Tomos I y II, Aranzadi, Camino de Galar, 15, Cizur Menor (Navarra), 2007.

GARCÍA DE ENTERRÍA, Eduardo; HERNÁNDEZ, Tomás-Ramón: Curso de Derecho Administrativo, I y II. 11. a edición, Aranzadi, Camino de Galar, 15, Cizur Menor (Navarra), 2008

GARCÍA DE ENTERRÍA, Eduardo; MUÑOZ MACHADO, Santiago y MESTRE DELGADO, Juan Francisco: Código de las Leyes Administrativas, I y II, 15. a edición, Aranzadi, Camino de Galar, 15, Cizur Menor (Navarra), 2008.

ICAV (Ilustre Colegio de Abogados de Valencia): Errores judiciales cuando el sistema falla. El Legajo, $2 .^{\mathrm{a}}$ etapa, n. ${ }^{\circ} 21,2{ }^{\circ}$ trimes- $^{\circ}$ tre 2011.

INFORME ANUAL 2010: Resumen de las actividades del Tribunal de Justicia, del Tribunal General y del Tribunal de la Función Pública de la Unión Europea. Luxemburgo 2011. Fuente: www. curia.europa.eu

INFORME ANUAL 2010: Resumen de las actividades del Tribunal de Justicia, del Tribunal General y del Tribunal de la Función Pública de la Unión Europea. Luxemburgo 2011. Fuente: www. curia.europa.eu

KELSEN, Hans: El método y los conceptos fundamentales de la Teoría Pura del Derecho, Reus, Madrid, 2009.

KELSEN, Hans: Teoría general del Estado, Comares, Granada, 2002.

KELSEN, Hans: Teoría Pura del Derecho, 11. a edición, Porrúa, México, 2000.

MALEM SEÑA, J. F: El error judicial y la formación de los jueces, gedisa, Barcelona, 2008.

MANGAS MARTÍN, Araceli, y LIÑÁN NOGUERAS, Diego J.: Instituciones y Derecho de la Unión Europea, 6. ${ }^{\mathrm{a}}$ e., Tecnos, Madrid, 2010. 
MANGAS MARTÍN, Araceli y otros: CDFUE, artículo por artículo, Fundación BBVA. Madrid, 2008.

MANGAS MARTÍN, Araceli: TUE, tratado de funcionamiento y otros actos básicos de la UE, Tecnos, 15. . edición, Madrid, 2010.

MEJÍAS GÓMEZ, Juan Francisco: La mediación como forma de TJE, Grupo Editorial, El Derecho y Quantor, Madrid, 2009.

MINISTERIO DEL INTERIOR: El espacio europeo de libertad, seguridad y justicia, M. ${ }^{\circ}$ Interior, Secretaría Técnica, Madrid, 2000

MOLINA DEL POZO, Carlos Francisco: Tratado de Lisboa. TUE, TFUE y CDFUE, Universitaria Ramón Areces, Madrid, 2011.

MORTE GÓMEZ, Carmen: Cómo presentar una demanda ante el TEDH, Tirant lo Blanch, Valencia, 2011.

ORTEGA Y GASSET, J.; Sobre el fascismo. El Espectador. 2. ${ }^{\mathrm{a}}$ edición, Biblioteca Edaf, Madrid, 2004.

ORTELLS RAMOS, Manuel (Dir. y coor.) y AA. VV.: Introducción al Derecho Procesal, Aranzadi, Cizur Minor (Navarra), 2010.

RAWLS, John: Teoría de la Justicia. Fondo de Cultura Económica, Madrid, 1979.

TIEDEMANN, Klaus: Requisitos fundamentales de una regulación de la Parte General del Der. Penal. C. Heymanns Munich, 2001.

TRUYOL SERRA, A.: La integración europea. Análisis históricodocumental con textos y documentos [I Génesis y desarrollo de la Comunidad Europea (1951-1979)]. Tecnos, Madrid, 1999.

UÑA JUÁREZ, Octavio, Hernández Sánchez, Alfredo: Diccionario de Sociología, ESIC, Madrid, 2004.

VACAS GARCÍA-ALÓS, Luis Francisco, El derecho a la tutela judicial efectiva, La Ley, Madrid, 1996

VELASCO CABALLERO, Francisco: Administraciones públicas y derecho a la tutela judicial efectiva. la administración del derecho fundamental del artículo 24. 1 de la Constitución, Bosch, Barcelona, 2003.

VIDAL PRADO, C.: El impacto del nuevo Derecho europeo en los Tribunales Constitucionales, Colex. Madrid, 2004. 